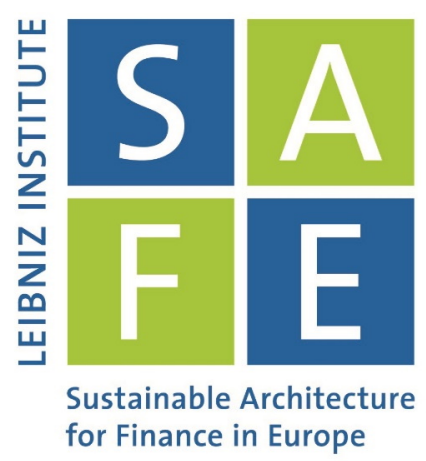

Andrea Modena

\title{
Recapitalization, Bailout, and Long-run Welfare in a Dynamic Model of Banking
}

SAFE Working Paper No. 292

\section{Leibniz Institute for Financial Research SAFE}

Sustainable Architecture for Finance in Europe 


\title{
Recapitalization, Bailout, and Long-run Welfare in a Dynamic Model of Banking*
}

\author{
by Andrea Modena ${ }^{\dagger}$
}

This Version: 14th October 2020

\begin{abstract}
This paper studies the link between bank recapitalization and welfare in a dynamic production economy. The model features financial frictions because banks benefit of a cost advantage at monitoring firms and face costly equity issuance. The competitive equilibrium outcome is inefficient because agents do not internalize the effects banks' capitalization over the allocation of capital, its price and, in turn, firms investments. It follows, individual recapitalizations are sub-optimal and bailout policies may benefit social welfare in the long-run. Bailouts improve capital allocation in states where aggregate banks are poorly capitalized, therefore enhancing their market valuation, fostering investments, and stabilizing the economy recovery path. (JEL D51, G21)
\end{abstract}

Keywords: Banks, bailout, general equilibrium, financial frictions, recapitalization, welfare.

* My gratitute goes to Markus Brunnermeier, Pietro Dindo, Giorgio Ferrari, Christian Kubitza, Marcella Lucchetta, Elisabetta Marzano (discussant), Francesco Menoncin, Sebastian Merkel, Giovanna Nicodano, Hendrik Hakenes, Roberto Savona, Isabel Schnabel, Paolo Pasquariello, Loriana Pelizzon, Jean-Charles Rochet, Paul Schempp, Christian Schlag, Javier Suarez, Jan Pieter Krahnen, and Raphael Repullo as well as to the participants to the VERA-Ca' Foscari Workshop in Macro-Finance (Venice), the Workshop in Stochastics for Economics and Finance (Siena), the finance group seminar at University of Bonn, the SAEe 2019 (Alicante), the EWMES 2019 (Rotterdam), the QFW2020 (Naples), and the student research seminars at Princeton University for the helpful conversations and suggestions. I gratefully acknowledge research support from the Leibniz Institute for Financial Research SAFE. All remaining errors are my own.

†University of Bonn amodena@uni-bonn.de 


\section{Introduction}

Over the last few decades, numerous countries dealt with a stern distress of their banking sector. Many crises stemmed into an impaired supply of those countries' financial services, and massive recapitalization decisions had to be taken. Most times, what followed was a major overhaul of a relevant share of the countries' banking sector, often finance by public money (bailout). In the EU only, no less than 114 banks benefited from government support during the period 2007-2013. Over the same time span, the European Commission (2019) reports that about $3 \%$ of EU 2012 GDP has been provided by member states as new capital to ailing banks. In recent years, especially after the sub-prime financial crisis, this resulted into public discontent against the policy of "privatizing profits and socializing losses".

On this subject, it is by now common knowledge that bailouts may lead to moral hazard, and eventually prompt excessive risk taking by the institutions that shall be virtually rescued (Hryckiewicz, 2014). Similarly, open ended liquidity support and repeated recapitalization with no control upon consequential risk taking may hinder the process of recovery (Honohan and Klingebiel, 2000). Yet, other studies argue that, by announcing and committing exante to bailout insolvent institutions in times of adverse conditions, the risk-reducing that comes after the so-called "value effect" outweighs the moral hazard component of the policy (Cordella and Yeyati, 2003; Sarin and Summers, 2016). ${ }^{1}$

As a result, both public and academic debate struggled upon the relative convenience of different recapitalization regimes: should the cost of banks distress be a burden to their own shareholders only, or should it be tax-financed? Are individual banks recapitalization choices also socially optimal? In there any room for a bailout to be beneficial?

While the moral hazard problem after banking resolution has been already extensively discussed, its macroeconomic spillover as well as the trade-off between long-run benefits and short-run costs of bailouts still deficits a proper treatment in the theoretical banking literature. This is mainly due to the dominant partial equilibrium paradigm in structural

\footnotetext{
${ }^{1}$ For instance, Gropp et al. (2010) argue that there is no evidence that public guarantees increase the protected banks' risk-taking, except for banks that have outright public ownership. In this regard, Lambrecht and Tse (2019) recently propose a theoretical model where, even without considering to role of bailouts at containing systemic risk, from a micro-prudential perspective, banks create the most value net of any recapitalization costs under bailout regimes.
} 
models of bank capital.

This paper aims at filling that gap by developing a suitable dynamic general equilibrium model of a production economy with a banking sector and financial frictions. Its main contribution is to frame a novel mechanism that links bank resolution regimes to their macroeconomic outcomes and, in turn, households' long-run welfare.

We provide theoretical evidence that, as long as agents fail at internalizing the aggregate outcome of their individual choices, the reallocation of resources within the economy may act as an engine to foster growth, and therefore there is room to consider a bailout recapitalization (Hoggarth et al., 2002; Bernanke, 2009). In other words, our results suggest that short-run recapitalization costs shall be accounted for jointly with the long-run benefit of a more stable and profitable financial system.

We consider an infinite horizon continuous-time economy populated by productive firms, banks, households, and a government sector. Firms are constituted by capital transfers from either households or banks versus the issuance of risky claims written on their profits. They are homogeneous and uniformly exposed to a common source of systematic risk. They collect capital stock, issue risky claims, and optimally choose the re-investment rate of capital to maximise the expected return on their claims.

Households maximise the inter-temporal utility of their consumption and allocate their net worth between banks' equity, short-term liabilities, and direct investments in firms issued risky claims.

Banks are owned and managed by households. They are useful for two reasons: first, they provide capital services because they are more efficient than households at monitoring firms' productive activities; second, they provide liquidity services by issuing risk-free short-term liabilities. By doing so, they raise additional resource that, jointly with their own equity endowment, they allocate in firms issued risky claims. Banks regulate their capital structure either by paying out dividends or issuing (costly) equity to maximise their market value.

The government sector has a re-distributive role: it imposes lump sum taxes to finance wealth transfers from households' net worth to banks' equity (bailout) and pays the associated administrative cost. It does so to maximise long-run social welfare.

We characterise the economy competitive equilibrium and show that: i) bailout recapit- 
alizations may generate a pecuniary externalities on banks market valuation by affecting the marginal value of their equity and, in turn, their capital structure and leverage strategies; ii) in a competitive economy where banks provide capital services such as efficient monitoring, their leverage determines the overall capital allocation, its price, and so the economy aggregate productivity. It other words, bailout recapitalization generate a pecuniary externality on capital prices, therefore influencing firms' investment policies.

Due to the pecuniary externalities in i) and ii), that is, different recapitalization regimes jointly affect the equilibrium prices of capital and banks' equity: iii) a bailout recapitalization regime may improve the capital allocation in states of distress, where the aggregate banking sector capitalization is scarce. This happens because, in a perfectly competitive environment, atomistic economic actors fail at internalizing the effect of their relative size over equilibrium outcomes. In other words, choices that hold as optimal from the individual standpoint (in the short-run) may not be so from the social perspective (in the long-run).

What is relevant to stress is that, in our model, due to the assumption of firms homogeneity with respect to systematic risk, distress contingencies to each bank (equity issuance) are always synchronous. As such, individual recapitalization strategies turn out to be socially sub-optimal because banks fail all at once, and their capacity of supplying liquidity and capital services is structurally compromised. It follows, a tax-financed bailout regime that complements individual recapitalization policies may improve social welfare. This results squares nicely with a recent study by Beck et al. (2020) showing that systematic risk increases more for economies whose banks are regulated by a more comprehensive resolution regime after negative system-wide shocks.

Another important aspect of our model concerns the relationship between banks recapitalization and macroeconomic dynamics. Additional equity issuance financed by taxation structurally reduces banks' leverage, thereby stabilizing their recovery path, increases capital prices and, in turn, investments. Also, it decreases the marginal value of banks' equity, thereby increasing the likelihood of those states where leverage is lower, and dividend payouts more frequent. This result is fundamentally in line with a recent study by Homar and van Wijnbergen (2017) showing that early interventions preserve the functions of the financial 
system, therefore mitigating the macroeconomic consequences of a crisis. ${ }^{2}$

In summary, the theoretical results of our model suggest that, even when all economic actors are homogeneous and all firms are subject to a common source of aggregate risk, there exists a trade-off between costs and benefits of banks bailout recapitalization. On the one hand, additional costs imposed to households by taxation associate to a reduction of their short-run welfare. On the other hand, those extra resources smoothen the transition through "bad states" where banks' leverage is high and the economy unstable. This reduces the likelihood of additional recapitalization due to high volatility-leverage and, via a positive feedback loop, allows banks to rapidly rebuild their own equity by retaining dividends.

The paper proceeds as follows. Section 1.1 outlines the relationship between our results and the incumbent literature. Section 2 introduces productive firms (2.2), and the government sector (2.3). Then, it discusses households' and banks' problems (2.4). Section 3 derives, solves, and discusses the competitive equilibrium in absence of government intervention (3.1-3.2). Section 4 extends the baseline scenario by including the bailout regime, and explores how it affects social welfare (4.2). Section 5 concludes.

\subsection{Related literature}

This paper belongs to the Macro-finance (MF) and intermediary asset pricing literature in presence of financial frictions (see He and Krishnamurthy, 2011, 2013, 2019; Brunnermeier and Sannikov, 2014, 2016; Phelan, 2016; Dindo et al., 2019, among others). ${ }^{3}$ Also, it relates to the theoretical stream of research on Banks Capital Structure (CS) (see for example Flannery, 1994; Hilscher and Raviv, 2014), especially to those studies deploying continuoustime structural models of endogenous default (D) to study bank recapitalization regimes (e.g. Leland, 1994; Løkka and Zervos, 2008). ${ }^{4}$

Similar to Klimenko et al. (2016), we extend the traditional (CS) and (D) partial equilib-

\footnotetext{
${ }^{2}$ Recent empirical evidence that bailout policies in the EU were able to enhance economic conditions is also in Barucci et al. (2019). Further evidence that, when there are too many banks to liquidate, the regulatory intervention in the form of bailing out some banks may be optimal in order to avoid allocation inefficiencies is in Caprio and Klingebiel (1996) and Acharya and Yorulmazer (2007).

${ }^{3} \mathrm{~A}$ comprehensive summary can be found in Cochrane (2017).

${ }^{4}$ Two very recent papers studying the relationship between banks capital bail-ins, and bailouts in a partial equilbrium setup are, among others, Berger et al. (2019); Leanza et al. (2019).
} 
rium environment by embedding financial frictions based model of bank capital structure in a general equilibrium setting. However, by building on Brunnermeier and Sannikov (2014), we further enhance our model by characterizing the relationship between banks recapitalization regimes, capital (and asset) prices, and firms investment choices (MF).

In line with the $(\mathrm{MF})$ literature, the presence of financial frictions in our model channels (socially) sub-optimal agents' choices at the individual level, and explain them via pecuniary externalities. However, different from previous studies, our unified framework highlights the role of a government bailout at redistributing resource across agents, and therefore at affecting equilibrium outcomes.

Two seminal contributions studying the efficiency of financial recapitalization in a general equilibrium static setting are Gorton and Huang (2004) and Philippon and Schnabl (2013). In Gorton and Huang (2004), they show that there is room for the government to supply liquidity financed by tax revenue. In our model, we reach similar conclusion, although in a very different framework. In this paper, the allocation efficiency that comes after bailout capital injections happens via pecuniary externalities and has its counterpart in banks capital structure. On the contrary, in Gorton and Huang (2004) it stems from liquidity issues.

Philippon and Schnabl (2013) study governmental interventions to recapitalize a banking sector that restricts lending to firms because of its debt overhang. They find that efficient recapitalization policies request equity versus cash injections rather than other common forms of intervention, such as asset purchases and debt guarantees. ${ }^{5}$ In their paper, government interventions generate two sources of rents: macroeconomic, occurring because of general equilibrium effect, and informational. In our model, we exclusively focus on the former, although we loosely account for the latter by introducing banks efficiency edge at monitoring. ${ }^{6}$

Another important contribution addressing the relationship between banking regulation, welfare, and efficiency is Nicolo et al. (2014). From a general point of view, we essentially set apart because we consider a general equilibrium productive economy instead of a partial

\footnotetext{
${ }^{5}$ This is because the former requires that banks share their upside with the government who financed them, that gradually reduces its participation in the supported banks.

${ }^{6}$ To this respect, the mechanism we propose also relates to Hennessy (2004). The paper incorporates debt in a dynamic real options framework, and shows that underinvestment stems from truncation of equity's horizon to default. Similarly, in our model equilibrium investments depends on prices (Tobin's $Q$ ), themselves a function of the banking sector recapitalization.
} 
equilibrium environment. Moreover, we focus on the complementary role of individual banks recapitalization versus bailout regimes rather than on banks micro-prudential regulation.

Recent relevant papers modelling a banking sector in a dynamic general equilibrium setting are Sandri and Valencia (2013); Phelan (2016); Nuno and Rey (2017); Gale et al. (2018).

Sandri and Valencia (2013) study a DSGE model where financial frictions are introduces by a financial accelerator mechanism. They show that recapitalizing the financial sector as a response to large losses in its net worth may be welfare improving because the latter relates to the fluctuations of output. Conversely, we focus on the pecuniary externalities that associate to banks recapitalization and their effect on the macroeconomic dynamics.

In Phelan (2016), the attention is on the role of leverage constraints at stabilizing the business cycle, while the possibility of default and bailouts is not accounted for. In Nuno and Rey (2017), instead, the focus is on the heterogeneity across banks.

Hugonnier and Morellec (2017) investigate the effects of liquidity and leverage requirements on banks' financing decisions and insolvency risk. They show that liquidity requirements lead to milder bank losses when defaulting, at the cost of an increased likelihood of default. On the other hand, higher leverage requirements reduces both likelihood of default and magnitude of bank losses after defaults. The main differences with this study is that Hugonnier and Morellec (2017) take the dynamics of return on risky claims in which banks invest their assets as given (it is not a productive economy). Therefore, firms' investments do not relate to banks' capitalization through equilibrium prices. An important common element is instead the costly issuance of new capital.

This work also relates to a recent paper by Mendicino et al. (2019) studying the relationship between short-run costs and the long-run benefits of capital requirement. Their paper shows that capital requirements make banks safer by addressing long-run stability risks. However, the associated (short-run) costs negatively impact aggregate demand. Differently from this paper, they address the issue as related to monetary policy, and show that as long as nominal rates do not hit the zero lower bound, monetary policy is effective at dampening the real effect of those costs. We basically differentiate because we focus on the positive feedback loop (long-run benefit) that associates to the short-run cost of recapitalization. 


\section{Model}

Before presenting the model economy in greater detail, we briefly overview the overall structure, actors, and main assumptions.

\section{$2.1 \quad$ Environment}

Time is continuous and infinite. The economy features two goods: physical capital (such

as trees, henceforth "capital") and perishable output good (such as apples) as well as four actors: productive firms, households, banks, and a government sector.

The total amount of assets within the economy at each time $t$ consists of the aggregate capital stock $K_{t}$; its market value sums up to households' plus banks' total net worth. All agents are price taker and exchange capital on frictionless markets at the competitive price $q_{t}$; output acts as numéraire.

Productive firms are infinitely lived. They are constituted at time zero via capital transfers from either households or banks. At each instant of time, they either receive additional transfers or pay back a fraction of their outstanding holdings to their shareholders. In other words, firms act as capital lessors. This gives rise to a moral hazard problem on capital markets as in Tirole (2010) that can be tackled by implementing costly monitoring. We assume that: both households and banks do so by paying a fixed monitoring cost for unit of capital deployed to constitute firms or transferred consequentially; banks provide the economy with capital services because their monitoring activity is more efficient than that of households.

Firms have two roles: first, they operate e neoclassical $A K$ technology producing output (apples) by using capital (trees); second, they re-invest a fraction of their production to intertemporally generate new capital via a stochastic technology whose productivity is affected by systematic shocks that are common across firms. They pay out the residual (not re-invested) share of output to their shareholders as dividends; the sum of dividend payouts plus capital gains can be interpreted as a return on risky claims written on firms' profits.

Similar to firms, households are infinitely lived. However, they are born at time zero with an initial endowment of capital, a fraction of which is exogenously allocated to constitute bank equity. Households consume and allocate the remainder of their net worth to 


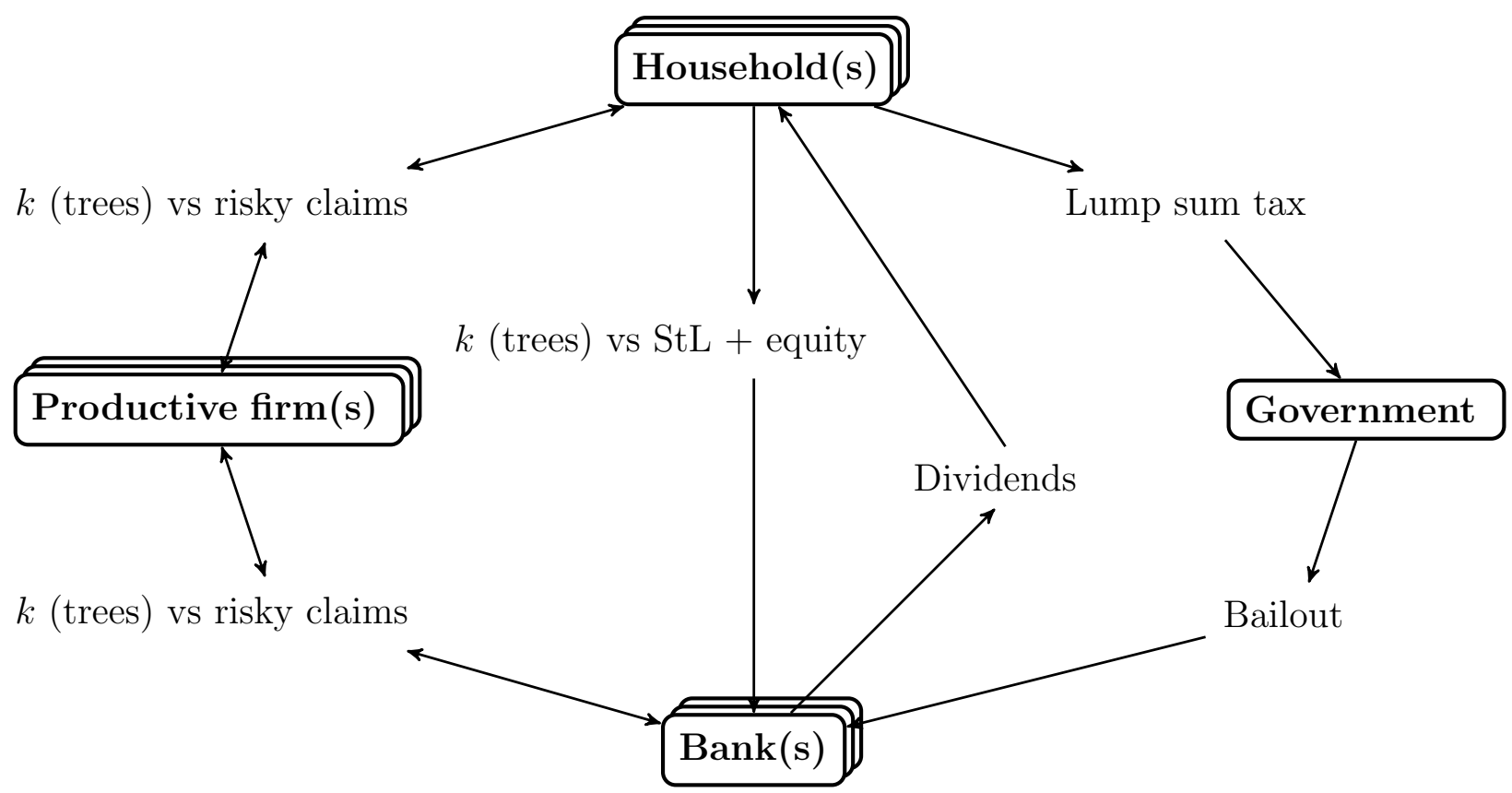

Figure 1: Cross relationships among productive firms, households, banks, and the government.

either firms issued risky claims or banks Short-term Liabilities (StL). The latter are valuable because they provide households with liquidity services.

Banks are constituted at time zero out of households' initial endowment. They issue StL and invest in firms issued risky claims. They optimally choose their capital structure (leverage), dividends payouts, and (costly) equity issuance to maximize their own market value. For sake of simplicity, we assume that households exclusively own and manage banks. Therefore, we abstract from any agency issues between them, and the aggregate banking sector is owned by the collectivity of households. ${ }^{7}$

The government sector has a re-distributive role, and may impose lump sum taxes to financing wealth transfers from households' net worth to banks' equity (bailout). To summarise, Figure 1 depicts the cross relationships among productive firms, households, banks, and the government.

\footnotetext{
${ }^{7}$ The model can be easily generalised to account for moral hazard by assuming that banks are owned by households but managed by financial intermediaries while imposing a suitable Incentive Compatibility (IC) constraint. Details are in Appendix A.
} 


\subsection{Firms, technologies, and costly monitoring}

There exists a continuum of productive firms indexed $i \in \mathbb{I}:=[0,1)$. They operate a neoclassical $A K$ technology producing perishable output good $y_{t}^{i}$ (apples) by using capital as an input:

$$
y_{t}^{i}=A k_{t}^{i},
$$

where $A$ can be interpreted as the marginal capital productivity net of the average depreciation rate.

Firms are also equipped with a stochastic technology that inter-temporally generates new capital (trees) by re-investing a share $\iota_{t}^{i}$ of total output. Let $d W_{t}$ be a standard Brownian motions defined on the filtered probability space $(\Omega, \mathcal{H}, \mathbb{P})$, where $\left\{\mathcal{H}_{t}, t>0\right\}$ is the natural filtration over the measurable space $(\Omega, \mathcal{H})$. The capital stock $k_{t}^{i}$ re-generated by firm $i$ evolves with dynamics:

$$
d k_{t}^{i}=k_{t}^{i}\left[\Phi\left(\iota_{t}\right) d t+\sigma d W_{t}\right], \text { with } \Phi(\iota)=\frac{\log (1+\theta \iota)}{\theta},
$$

where $\sigma \in \mathbb{R}^{+}$is a constant diffusion term. The concave function $\Phi(\bullet)$ is equivalent to a standard investment technology with convex adjustment cost where $\theta$ parametrizes technological illiquidity (on this point, see Brunnermeier and Sannikov, 2016). What is relevant to stress is that $d W_{t}$ represents the unique source of risk within the economy, and is common across all firms.

Productive firms have no initial endowment on their own. They are constituted at time zero by transfers of capital $k_{0}^{i}$, valued $q_{0} k_{0}^{i}$, either from banks $(i=b)$ or directly from households $(i=h)$. Then, at each time $t$, they continuously receive additional transfers $\left(d k_{t}^{i}>0\right)$ or pay back $\left(d k_{t}^{i}<0\right)$ a fraction of their outstanding holdings to their shareholders depending on the latter's portfolio choices. Accordingly, firms finance their activities by issuing risky claims written on their profits whose returns have the following structure:

$$
d R_{t}^{i}=\mu_{t}^{i} d t+\sigma_{t} d W_{t}
$$

where the expected return $\mu_{t}^{i}$ and volatility $\sigma_{t}$ terms are endogenously determined in equilib- 
rium. Firms' optimal re-investment rate $\iota_{t}^{i}$ relates to the price of capital $q_{t}$ by the so-called Tobin's Q:

$$
\partial_{\iota} \Phi\left(\iota_{t}^{i}\right)=\frac{1}{q_{t}} \Rightarrow \iota_{t}^{i}=\iota_{t}, \forall i \in \mathbb{I},
$$

and is homogeneous across firms. Details on firms' problem and the analytical derivation of their optimal policies can be found in Dindo et al. (2019).

Price dynamics and return on risky claims In order to characterize the return on firms issued risky claims, one may postulate a stochastic process that describe the dynamics of capital price $q_{t}$. As the only source of uncertainty in our economy is the systematic risk $d W_{t}$, we conjecture $q_{t}$ to evolve as an Itô's diffusion:

$$
\frac{d q_{t}}{q_{t}}=\mu_{t}^{q} d t+\sigma_{t}^{q} d W_{t}
$$

where the drift $\mu_{t}^{q}$ and diffusion $\sigma_{t}^{q}$ terms are $\mathcal{H}$-adapted stochastic processes whose values are endogenous and will be determined in equilibrium. By Itô's lemma, given the output production function (1), the investment technology (2), and the conjectured processes in (5), the return on firms issued risky claims evolves as (3), where: ${ }^{8}$

$$
\mu_{t}^{i}:=\underbrace{\frac{A-\iota_{t}}{q_{t}}}_{\text {Dividend Yield }}+\underbrace{\Phi\left(\iota_{t}\right)+\mu_{t}^{q}+\sigma_{t}^{q} \sigma}_{\text {Capital Gain }} ; \quad \sigma_{t}:=\sigma+\sigma_{t}^{q} .
$$

Costly monitoring Neither households nor banks directly hold capital stock, that is managed on their behalf by productive firms. Via exerting costly effort, firms can enhance their individual output productivity. This gives rise to a moral hazard problem on capital markets that can be either tackled indirectly, by writing suitable contracts between the firms and their shareholders, or directly, by implementing costly monitoring of firms' effort decisions (Diamond, 1984; Tirole, 2010).

\footnotetext{
${ }^{8}$ As in Brunnermeier and Sannikov (2014), the left-hand side component of the drift term $\mu_{t}$ can be interpreted as firms' dividend yield. The former addend is proportional to the marginal capital productivity net of re-investment $\left(A-\iota_{t}\right)$, and summarises the stock of output that is deployed to generate new capital. Complementarily, the right-hand side term captures capital gains, that is, the instantaneous stock plus value change in firms' managed capital that associates to their re-investment policies.
} 
In this setting, we assume that: direct monitoring is always more convenient than contracting, and therefore it is optimal to pay the associated cost; banks are more efficient than households when dealing with firms, that is, their monitoring costs are lower. Similar to Ghote (2020), we model households' and banks' monitoring costs so that they scale down the return on firms issued risky claims by a fixed amount $\eta^{j}$, with $j \in\{h, b\}$, for unit of allocated capital. Accordingly, we define banks' "efficiency edge" as

$$
\eta:=\eta^{h}-\eta^{b} \geq 0
$$

that can be read as a reduced form that captures banks' expertise at providing capital services. Banks' efficiency edge and their liquidity supply via StL are the only reasons that motivate the existence of banks in our model. For sake of simplicity we set $\eta^{b}=0$ and, by (7), $\eta^{h}=\eta$. The rationalization of banks' efficiency edge is discussed in greater detail in Appendix B.

\subsection{Government, taxes, and bailout}

The economy features a government sector who collects lump sum taxes $d T_{t}^{\pi}$ over the time interval $[t, t+d t)$. The tax aims at financing aggregate wealth transfers from households' to banks' net worth that complement individual banks' equity issuance. Therefore, it can be interpreted as a bailout.

The government carries out tax financed bailouts contingent on an exogenous Recapitalization Thresholds (RT). It does so in households' best interest, that is, looking forward to maximise ex-ante social welfare. The RT can be thought as the minimal required capital buffer that is regarded as necessary for the banking sector to work. More specifically, government bailout policies are characterise as follows. First, the total stock of tax revenues is evenly rebated across all banks. Second, a fraction of total revenues is depleted after the payment of fixed administrative costs $\lambda^{G} \in \mathbb{R}^{+}$for unit of capital. It follows, total bank recapitalizations $d T_{t}^{\pi} \operatorname{costs} d T_{t}^{\pi}\left(1+\lambda^{G}\right)$ in terms of households' net worth. 


\subsection{Households and banks}

Households There exists a continuum of households indexed $h$ and defined over the space $\mathbb{H}:=[0,1)$. They are risk-neutral, infinitely lived, and discount the future at a constant rate $\rho$. Households are born at time zero with an initial endowment $e_{0}$, a fraction of which is exogenously allocated as banks' equity, of which they are managers and shareholders. As such, they receive dividends flows $d \Delta_{t}^{b}$ and pay for the countervalue of they own bank's equity issuances $d \Pi_{t}^{b}$.

As for government bailouts, individual banks recapitalization is costly. Similar to Løkka and Zervos (2008) and Klimenko et al. (2016), we assume that issuing bank equity entails the payment of $\lambda \leq \lambda^{G} \in \mathbb{R}^{+}$units of capital as a fixed cost. It follows, the instantaneous flow of resources depleted after bank's $b$ recapitalization equals $d \Pi_{t}^{b}(1+\lambda)$, where the parameter $\lambda$ summarizes banks administrative and organizational costs for issuing new equity. ${ }^{9}$

Households gain utility from consumption and allocate their resources between bank equity $e_{t}^{b}$, valued $\nu_{t} e_{t}^{b}$, StL $d_{t}^{h}$ remunerated at the risk-free rate $r_{t}$, and firms issued risky claims with return $d R_{t}^{i}$, valued $q_{t} k_{t}^{h}$. Therefore, household's $h$ net worth at time $t$ equals:

$$
e_{t}=\nu_{t} e_{t}^{b}+\underbrace{d_{t}^{h}+q_{t} k_{t}^{h}}_{e_{t}^{h}}
$$

where $e_{t}^{h}$ denotes the fraction of household's $h$ net worth that is not allocated in bank equity.

Households value banks' StL for their liquidity services. Accordingly, they enjoy a flow of utility $\Gamma\left(d_{t}^{h}\right) d t$, where $\Gamma(\bullet)$ is an increasing and concave function. ${ }^{10}$ Formally, households' problem reads as follows:

$$
H_{0}^{h}:=\sup _{\left\{c_{t}^{h}, d_{t}^{h}, k_{t}^{h}\right\} \in G_{t}^{h}} \mathbb{E}_{0} \int_{0}^{\infty} e^{-\rho t}\left[c_{t}^{h}+\Gamma\left(d_{t}^{h}\right)\right] d t,
$$

\footnotetext{
${ }^{9}$ Loosely speaking, this friction may be also thought as a reduced form that captures the market illiquidity that banks face when they need to issue securities in a the moment of distress. Empirical evidence of the negative relationship between stock liquidity and its issuance costs is in Butler et al. (2005).

${ }^{10}$ Note that the technological and informational frictions of our model is not as strong as in Klimenko et al. (2016), although it still holds in a reduced form. In this regard, banks advantage at monitoring firms is summarized by the parameter $\eta$. It follows, households direct capital allocations in firms issued risky claims are an equilibrium outcome.
} 
subject to the dynamic budget constraint

$$
G_{t}^{h}: d e_{t}=r_{t} d_{t}^{h} d t+\underbrace{q_{t} k_{t}^{h} d R_{t}^{i=h}}_{\text {Return on risky claim }}-\underbrace{\eta k_{t}^{h} d t}_{\text {Monitoring cost }}+d\left(\nu_{t} e_{t}^{b}\right)-c_{t}^{h} d t+d T_{t}^{h},
$$

where $d\left(\nu_{t} e_{t}^{b}\right)$ denotes the return on bank's $b$ equity, and $d T_{t}^{h}:=-d T_{t}^{\pi}\left(1+\lambda^{G}\right)$ is the instantaneous government lump sum tax.

Banks There exists a continuum of banks indexed $b$ and defined over the space $\mathbb{B} \in[1,2)$. Banks are owned and managed by households who choose dividend payouts, equity issuance, and leverage to maximize banks' market value. Each bank can borrow - issue short-term liabilities - at a rate $r_{t} \leq \rho$, and faces a fix cost $\lambda \in \mathbb{R}^{+}$for issuing new equity. Formally, banks' problem reads as follows:

$$
J_{0}^{b}:=\sup _{\left\{d_{t}^{b}, k_{t}^{b}, d \Delta_{t}^{b}, d \Pi_{t}^{b}\right\} \in B_{t}^{b}} \mathbb{E}_{0} \lim _{T \rightarrow \infty} \sup _{\tau \in[0, T)} \int_{0}^{\tau \wedge T} e^{-\rho t}\left[d \Delta_{t}^{b}-(1+\lambda) d \Pi_{t}^{b}\right],
$$

subject to the dynamic budget constraint

$$
B_{t}^{b}: d e_{t}^{b}=q_{t} k_{t}^{b} d R_{t}^{b}+d_{t}^{b} r_{t} d t-d \Delta_{t}^{b}+d \Pi_{t}^{b}+d T_{t}^{\pi}
$$

where $d \Delta_{t}^{b}:=d \delta_{t}^{b} e_{t}^{b}$ is the absolute value of dividend payouts, $d \Pi_{t}^{b}:=d \pi_{t}^{b} e_{t}^{b}$ the absolute value of equity issuances, $d T_{t}^{\pi}$ is the absolute value of government bailout, and $\tau$ represents the equity issuance time $\tau:=\inf \left\{t \in[0, \infty): e_{t}^{b} \leq 0\right\}$, i.e. $\tau$ is an $\mathcal{F}_{t}$ - stopping time. ${ }^{11}$

In order to find the optimal stopping time $\tau$, one must set the proper boundary conditions to Problem (11) (see Stokey, 2009, Chapter 6). Consider the following:

$$
J^{b *}\left(e_{t}^{b}\right)=\sup _{\left\{d_{t}^{b}, k_{t}^{b}, d \Delta_{t}^{b}, d \Pi_{t}^{b}\right\}} J_{t}^{b}\left(d_{t}^{b}, k_{t}^{b}, d \Delta_{t}^{b}, d \Pi_{t}^{b}, e_{t}^{b}\right)
$$

Due to the continuity of $d W$, the bank $b$ never expires her capital over the interval $d t$. Moreover, by considering the time value of money, it is always optimal to delay the issuance

\footnotetext{
${ }^{11}$ Note that, formally, it is also required that $\Delta^{b}$ and $\Pi^{b}$ are $\mathcal{F}_{t}$ increasing cádlág processes, and $d \Delta_{t}^{b} \leq e_{t}^{b}$ $\forall t \geq 0 P-a . s$., for ruling out the possibility of making dividend payments greater than the bank's reserves.
} 
of new equity as long as $e_{t}^{b}>0$. Accordingly, there does exist some arbitrary $\epsilon>0$ such that it is optimal to rise new equity before $d e_{t}^{b}$ reaches $(-\infty, 0)$. The suitable boundary condition is given by the so-called smooth pasting condition. ${ }^{12}$

By considering the recursive structure of Problem (11) jointly with (13), the optimal banks' strategy that defines $\tau$ either let the equity process $(12)$ hit the boundary $(-\infty, 0]$ (absorbing barrier) or it prevents the process from reaching $(-\infty, 0]$ (reflecting barrier). Accordingly, banks' problem must be complemented with the following:

$$
\max \left\{-J^{b *}(0), \partial_{e} J^{b *}(0)-(1+\lambda)\right\}=0
$$

In Appendix $\mathrm{C}$, we provide a heuristic proof that as long as $\lambda<\infty$, then $\tau=\infty \Longleftrightarrow$ $\partial_{e} J^{b *}(0)=1+\lambda$. In other words, when the recapitalization cost is not too big, then it is always optimal to recapitalize bank $b$ when she goes bankrupt. Then, banks' problem reduces to:

$$
\rho J_{t}^{b}:=\sup _{\left\{d_{t}^{b}, k_{t}^{b}, d \Delta_{t}^{b}, d \Pi_{t}^{b}\right\} \in B_{t}^{b}}\left\{d \Delta_{t}^{b}-(1+\lambda) d \Pi_{t}^{b}+\frac{1}{d t} \mathbb{E}_{t} d J_{t}^{b}\right\},
$$

with transversality condition $\lim _{t \rightarrow \infty} \mathbb{E}_{0} e^{-\rho t} V_{t}^{b}=0$.

To briefly summarise the relationship between households and banks with respect to their assets holdings, Figure 2 provides a snapshot of their balance sheet at time $t$.

\section{Competitive equilibrium and numerical solution}

This section defines and characterises the competitive equilibrium (3.1). Then, 3.2 provides a numerical solution and discusses the results associated to the baseline model with no government bailout.

Informally, the competitive equilibrium of this economy consists of a map from histories

\footnotetext{
${ }^{12} \mathrm{~A}$ formal statement for the more general case when the drift of banks' equity is positive jointly and a proof of uniqueness is in Løkka and Zervos (2008). In this regard, they show that bankruptcy happens at the time when banks' equity (due to homogeneity, here also in the aggregate) hits the boundary $(-\infty, 0)$ instead of $(-\infty, 0]$ because, otherwise, there does not exist an optimal recapitalization strategy $d \Pi_{t}^{b}$. A model where a positive capital buffer before banks recapitalization may be obtained by introducing discontinuities in the noise process, such as Poisson jumps, rather than postulating delays when banks collect new capital on the markets as for example in Peura and Keppo (2006).
} 


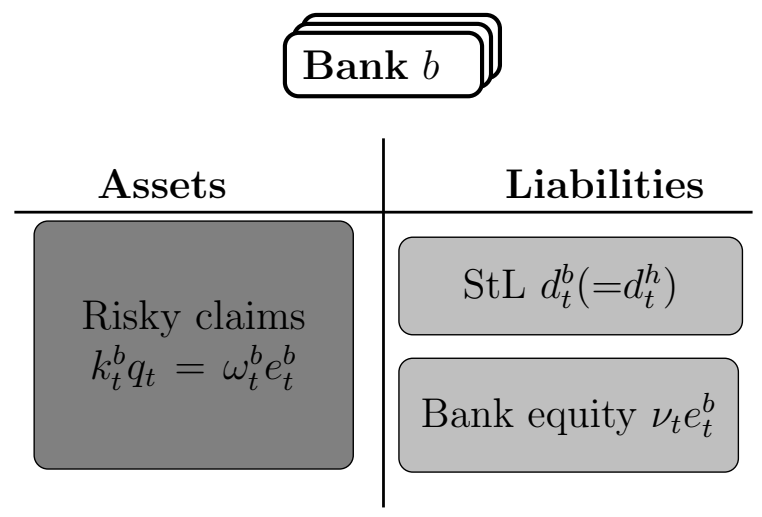

Household $h$

Figure 2: Banks' and households' balance sheet at time $t$.

of systematic shocks $\left\{d W_{t}\right\}$ to prices $\left\{q_{t}, \nu_{t}\right\}$, returns on firm risky claims $\left\{d R_{t}\right\}$, risk-free rates on banks' short-term liabilities $\left\{r_{t}\right\}$, production $\left\{K_{t}, \iota_{t}\right\}$ and consumption choices $\left\{c_{t}^{h}\right\}$, capital allocations $\left\{k_{t}^{h, b}, d_{t}^{b}\right\}$ as well as dividends payouts and equity issuance strategies $\left\{d \Delta_{t}^{b}, d \Pi_{t}^{b}\right\}$ so that: firms maximise their profits, households maximise their utility, banks maximise their market value, and all markets clear (consumption, capital, and banks' StL). The formal statement of the equilibrium is in Appendix F.2.

\subsection{Equilibrium characterization}

The optimality conditions that characterise households' strategies read as follows.

\section{Proposition 1. Households' strategies}

The individual households' strategies $\left\{d_{t}^{h}, k_{t}^{h}\right\}$ and $\left\{c_{t}^{h}\right\}$ that are optimal control to problem (9) satisfy the following:

1. Consumption is indeterminate; it is pinned down by market clearing conditions;

2. Households' portfolio choices are coherent with the following asset pricing (in)equalities:

$$
\begin{gathered}
r_{t}=\rho-\partial_{d} \Gamma\left(d_{t}^{h}\right), \\
\mu_{t}-\frac{\eta}{q_{t}} \leq \rho .
\end{gathered}
$$

Proof. See Appendix F.1. 
Households are willing to hold banks' StL at a rate of return lower than their discount $\rho$. In particular, the risk-free rate equals $\rho$ minus the marginal utility of banks' liquidity services (16). In a similar fashion, households are not willing to hold firms issued risky claims directly when (17) holds slack; they therefore mandate risky investments in firms to banks. They are indifferent otherwise, when (17) holds with equality.

As far as banks are concerned, all their optimal strategies are homogeneous in the net worth of their equity $e_{t}^{b}$. Accordingly, the proper ansatz for the value $J_{t}^{b}$ under the optimal strategy $\left\{d_{t}^{b}, k_{t}^{b}, d \Delta_{t}^{b}, d \Pi_{t}^{b}\right\}$ reads as follows (see also Brunnermeier and Sannikov, 2014).

$$
\nu_{0} e_{0}^{b}:=\mathbb{E}_{0} \int_{0}^{\infty} e^{-\rho t}\left[d \Delta_{t}^{b}-(1+\lambda) d \Pi \Pi_{t}^{b}\right],
$$

where $\nu_{t}$ can be read as the marginal value of a bank endowed with equity $e_{t}^{b}$, that is, the equilibrium market price of bank's $b$ equity. ${ }^{13}$

To further characterize the equilibrium, one shall postulate a stochastic process that describe the dynamics of the banks marginal value $\nu_{t}$. In this way, one can analytically derive the expected variation of the stochastic differential $d\left(\nu_{t} e_{t}^{b}\right)$ that appears in banks' HJBE (15). Since the unique source of uncertainty within the economy is $d W_{t}$, we postulate $\nu_{t}$ to also evolve as an Itô diffusion:

$$
\frac{d \nu_{t}}{\nu_{t}}=\mu_{t}^{\nu} d t-\sigma_{t}^{\nu} d W_{t}
$$

where $\mu_{t}^{\nu}$ and $\sigma_{t}^{\nu}$ are $\mathcal{H}$-adapted stochastic processes whose values are endogenous and determined in equilibrium. By (19), we restrict our search to those equilibria where after good (bad) shocks, banks marginal value is decreasing (increasing) since, due to leverage, their assets grows (shrinks) proportionally more than their liabilities. Individuals banks' strategies are summarised in the following proposition.

\footnotetext{
${ }^{13}$ More specifically, $\nu_{t} e_{t}^{b}$ represents the market value of bank $b$ at time $t$ or, in other words, the maximal expected net present value that the bank may attain conditional on having book value $e_{t}^{b}$. As we shall see, the non-linearities embodied in the equilibrium dynamics of $\nu_{t}$ imply that risk-neutral banks act as if they were risk-averse. The term $\nu_{t}$ is a proportionality coefficient that summarizes the way market conditions (other than the banks' own equity endowment) affect their market value. According to Phelan (2016); Klimenko et al. (2016) $\nu_{t}$ can be interpreted as the market-to-book value of bank $b$ so that $e_{t}^{b}$ represents the book value of bank $b$ equity. What is relevant to highlight is that, within the framework of the model, banks' equity is valued mark-to-market rather than at book values.
} 


\section{Proposition 2. Bank's strategies}

Conditional on (19), the individual banks' strategies $\left\{d_{t}^{b}, k_{t}^{b}, d \delta_{t}^{b}, d \pi_{t}^{b}\right\}$ that are optimal controls to problem (13) satisfy the following (in)equalities:

1. The dynamics of $\nu_{t}$ features upper and lower "reflecting barriers" and "singular controls" so that:

$$
1 \leq \nu_{t} \leq 1+\lambda, \quad \forall t \quad \text { and }
$$

(a) $d \delta_{t}^{b}>0 \Longleftrightarrow \nu_{t}=1, \quad d \delta_{t}^{b}=0 \quad$ else;

(b) $d \pi_{t}^{b}>0 \Longleftrightarrow \nu_{t}=1+\lambda, \quad d \pi_{t}^{b}=0 \quad$ else.

2. The drift of banks marginal value dynamics equals the marginal utility of banks' liquidity services:

$$
\mu_{t}^{\nu}=\rho-r_{t} \Rightarrow \mu_{t}^{\nu}=\partial_{d} \Gamma\left(d^{b}\right) .
$$

3. Banks' leverage - asset pricing condition - satisfies:

$$
\mu_{t}-r_{t} \leq-\frac{1}{d t} \operatorname{Cov}_{t}\left(\frac{d \nu_{t}}{\nu_{t}}, d R_{t}\right) ;
$$

(a) When (21) holds with equality bank $b$ is indifferent between holding risky stakes in firms or StL. Then, her leverage is strictly positive (StL are negative), and the Sharpe ratio $\left(S R^{b}\right)$ satisfies:

$$
k_{t}^{b}>0, \text { and } S R^{b}:=\frac{\mu_{t}-r_{t}}{\sigma_{t}}=\sigma_{t}^{\nu} .
$$

(b) Else, (21) holds slack and $k_{t}^{b}=0$

Proof. See Appendix F.3.

The first important implication of Proposition 2 is that there exists a one-to-one relationship between banks' dividend payouts (equity issuance) and the upper (lower) reflecting barrier of the equilibrium dynamics. Banks pay dividends at a rate $d \delta_{t}^{b}>0$ when the marginal value of their equity $\nu_{t}$ equals that of capital payouts. The state $\nu_{t}=1$ classifies the 
upper reflecting barrier of the equilibrium dynamics. ${ }^{14}$

Conversely, banks issue new equity at a rate $d \pi_{t}^{b}>0$ when the marginal value of their equity equals the marginal cost of recapitalization, i.e. one plus $\lambda$. The state $\nu_{t}=1+\lambda$ classifies the lower reflecting barrier of the equilibrium dynamics.

As we discussed at length in Section 2.4, the issuance of new equity takes place when banks cannot remunerate StL and $e_{t}^{b}>0$. Therefore, household $h$ (the bank $b$ shareholder) "withdraws" the counter-value $d \Pi_{t}^{b}$ from her holdings in short-term liabilities and direct investments in firms issued risky claims in order to keep the bank solvent. This mechanism grants the absolute safety of short-term liabilities over the interval $[t, s$ ) (as for example in Stein, 2012). In all intermediate states where $\nu_{t}$ assumes values between 1 and $1+\lambda$, banks neither pay dividends nor issue new equity. Therefore, banks capital structure is never trivial: they finance by retaining dividends/issuing equity when the collected resources marginally contribute to higher expected future dividends, by issuing StL otherwise.

The second point of Proposition 2 outlines the link between banks marginal value and liquidity services, i.e. the drift of (19) must equal household marginal utility of holding banks' StL.

The third and last result summarised in Proposition 2 concerns banks' leverage and asset pricing condition. The risk premium $\mu_{t}-r_{t}$ must be such that banks are indifferent between holding risky stakes in firms or StL. When choosing their optimal leverage, banks price risk by taking into account the covariance between the marginal value of their equity and the return on risky stakes in firms (the right-hand side of Equation 21). In this sense, risk neutral banks act as if they were risk averse (see also Brunnermeier and Sannikov, 2014; Phelan, 2016, for a similar result). As we shall see, the equilibrium risk premium relates to banks' precautionary motif, i.e. they are willing to leverage out the whole net wealth of households only when their capital buffer - equity - is big enough. In those states of the world, households entirely mandate to banks the investment in firms. Else, households do not utterly allocate their net wealth in StL; they invest a fraction of their net wealth in firms directly and pay the associated monitoring $\operatorname{cost} \eta$. In equilibrium, this fundamentally affect

\footnotetext{
${ }^{14} \nu_{t}$ can never be less one because banks might always pay out the full value of their equity instantaneously, guaranteeing a net value of at least $e_{t}^{b}$.
} 
the marginal productivity of physical capital, and so the equilibrium price $q_{t} .{ }^{15}$

The state variable We now have all necessary ingredients to formally define the (unique) state variable, banking sector relative capitalization, denoted $\psi$, jointly with the stochastic process that describes its dynamics.

We restrict our search to the class of dynamically simple equilibria in banking sector relative capitalization, that is, all relevant equilibrium aggregates can be expressed as functions of $\psi$, whose dynamics follows itself a diffusion process. The dynamically simple equilibrium is Markov (time homogeneous), and it is so that there exists an associated stationary distribution. Consistently, from now on we drop the time subscript $t$.

Let banks' relative capitalization be defined as

$$
\psi:=\frac{E^{b}}{E^{b}+E^{h}},
$$

where $E^{b}=\int_{\mathbb{B}} e^{b} d b$ and $E^{h}=\int_{\mathbb{H}} e^{h} d h$ are the aggregate net worth of banks and households, respectively. Henceforth, we refer to the aggregate of banks as Banking Sector. All relevant equilibrium quantities can be expressed as functions of $\psi$, whose dynamics is driven by a regulated diffusion process. The result is summarised in the following:

\section{Proposition 3. State dynamics}

The relative capitalization (22) of the banking sector has endogenous law of motion

$$
\frac{d \psi}{\psi}=\mu^{\psi}(\psi) d t+\sigma^{\psi}(\psi) d W+d \Xi
$$

where $d \Xi$ describes banks' aggregate dividend and equity issuance singular controls, and therefore regulates the diffusion dynamics. Moreover,

$$
\mu^{\psi}(\psi)=\frac{1}{\theta}\left(\frac{1+\theta A}{q(\psi)}-1\right)+\left[\sigma+\sigma^{q}(\psi)\right]\left\{\left[\omega^{b}(\psi)-1\right] \sigma^{\nu}(\psi)+\sigma+\sigma^{q}(\psi)\right\}
$$

\footnotetext{
${ }^{15}$ In the spirit of He and Krishnamurthy (2013), this is an intermediary asset pricing model. Therefore, the banks have a central role to determine the price firms issued risky claims that depends on the capacity of banks' equity to absorb risk. Empirical evidence that the marginal value of the financial sector wealth provides relevant information for asset pricing is in Adrian et al. (2014).
} 


$$
\begin{gathered}
\sigma^{\psi}(\psi)=\left[\omega^{b}(\psi)-1\right]\left[\sigma+\sigma^{q}(\psi)\right] ; \\
\omega^{b}(\psi):=\frac{K^{b} q(\psi)}{E^{b}} ; \\
d \Xi=\int_{\mathbb{B}}\left[d \delta^{b}-d \pi^{b}\right] d b
\end{gathered}
$$

where the couple

$$
\lim _{\psi \rightarrow 0} \nu(\psi)=1+\lambda ; \quad \nu(\bar{\psi})=1
$$

characterise the lower and upper boundaries $(0, \bar{\psi}]$ of the state space, respectively.

Proof. See Appendix F.4

What stands out from Proposition 3 is that, as long as banks' relative capitalization lays between the upper and lower bounds $\psi \in(0, \bar{\psi}]$, then $d \psi$ evolves as an Itô diffusion with drift $\psi \mu^{\psi}(\psi)$ and diffusion $\psi \sigma^{\psi}(\psi)$. Accordingly, the regulatory term $d \Xi$ must hold equal to zero (see also Proposition 2, point 1).

Conversely, when $\psi$ reaches the reflecting barriers, $d \Xi$ acts as an impulse that adjusts process (23) by creating a regulated diffusion. The "adjustment" takes place instantaneously when either the banking sector pays dividends or issues new equity, respectively. It follows, the upper and lower thresholds of $\psi$ uniquely relate to the upper and lower bounds of $\nu(\psi)$ that are determined by the cost of new equity issuance $\lambda .^{16}$

The choice of (22) as a state variable is particularly appropriate as there does not exist idiosyncratic risk affecting the net worth of any bank $b \in \mathbb{B}$. Thus, all banks are homogeneous in terms of their marginal value $\nu$ and their dividend payout and strategies are homogeneous in $e^{b}$. Therefore, when one bank either issue new equity or pays out dividends, the whole banking sector does so. For this reason, banks recapitalization is always synchronous to all banks and the marginal value of banks' equity can be characterized as $\nu(\psi)$. Accordingly, the upper and lower reflecting barriers read as $\nu(\bar{\psi})=1$ and $\lim _{\psi \rightarrow 0} \nu(\psi)=1+\lambda$, respectively.

\footnotetext{
${ }^{16}$ Note that, as long as $\lambda$ is different from zero, banks never pay dividends and issue equity at the same time. In the limit case where $\lambda=0$ there is no friction over banks' capital flows. Thus, the FOCs for $d \delta^{b}$ and $d \pi^{b}$ are such that $d \Delta>0, d \Pi>0 \Longleftrightarrow \nu_{t}=1, \forall t$, which means that the banks pay dividends and issue equity to keep $\psi$ at the current level where the marginal value of the banks' equity equals the marginal value of capital stock $(=1)$. We briefly discuss this benchmark case, where there are no banks and the economy is populated by households only in Appendix D.
} 
In a similar fashion, the relative capitalization of the banking sector also determines the equilibrium price of physical capital so that $q(\psi)$ (further details upon the derivations are in Appendix F.5).

\subsection{Numerical solution and discussion}

This section discusses the numerical solution of the model in the baseline case where the government does not rise taxes and $d T^{\pi}=0$. The solution method is similarly to Brunnermeier and Sannikov (2014); the details are discussed in Appendix F.5.

To the aim of this study, we assume $\Gamma\left(d^{h}\right)=\Gamma d^{h}$ so that the risk-free interest rate on banks' StL is constant and equals $r=\rho-\Gamma$. Henceforth, unless specified otherwise, all the equilibrium quantities are computed considering the following parametric values: $A=0.4$, $\eta=0.1, \sigma=0.25, \theta=2, \lambda=0.15, \rho=0.05, \delta=0.25$, and $\Gamma=0.015$. The implied upper threshold equals $\bar{\psi} \approx 0.285 .{ }^{17}$

Figure 3 (top) depicts the equilibrium values of prices (blue), investments (red), and marginal value of banks' equity as a function of the state $\psi$ in left and right panels, respectively. The same Figure (bottom) shows the Sharpe ratios for banks (solid) and households (dashed), as well as banks' equilibrium leverage in the left and right panels, respectively. The dotted red line highlights the upper capitalization threshold $\bar{\psi}$ at which banks pay out dividends. Instead, the green dotted line shows the threshold above which banks are capitalized enough to leverage all households' spare capital not already allocated in their equity, $\psi^{\nu}$ (henceforth capital allocation threshold), by issuing StL. Note that, above $\psi^{\nu}$, firms are exclusively constituted through banks $\left(\int_{\mathbb{B}} k^{b} d b=K, k^{h}=0\right.$, and $\left.\omega^{b}=\frac{1}{\psi}\right)$.

Pecuniary externalities, leverage, and Sharpe ratios Individual portfolio choices fundamentally associate to the aggregate capital allocation between households and banks,

\footnotetext{
${ }^{17}$ While these choices are not the result of calibration, they produce reasonable qualitative results. From the analysis of equilibrium outcomes it is straightforward that the model dynamics strictly relates to the marginal value of banks' equity, and so on level of the financial friction that determines the cost of their equity issuance at the lower threshold. As such, further questions may arise: how does the upper threshold changes with respect to the main parametric values? How does that relate to $\nu$ ? To answer these questions, a comparative statics analysis is in Appendix E. Note that the lower threshold at which banks issue new equity always equals zero as long as there is no delay at collecting capital from the households and the risk sources within the economy are of the diffusion type, i.e. shocks take place continuously. Thus, the only degree of freedom to define the equilibrium state-space is summarised by $\bar{\psi}$.
} 

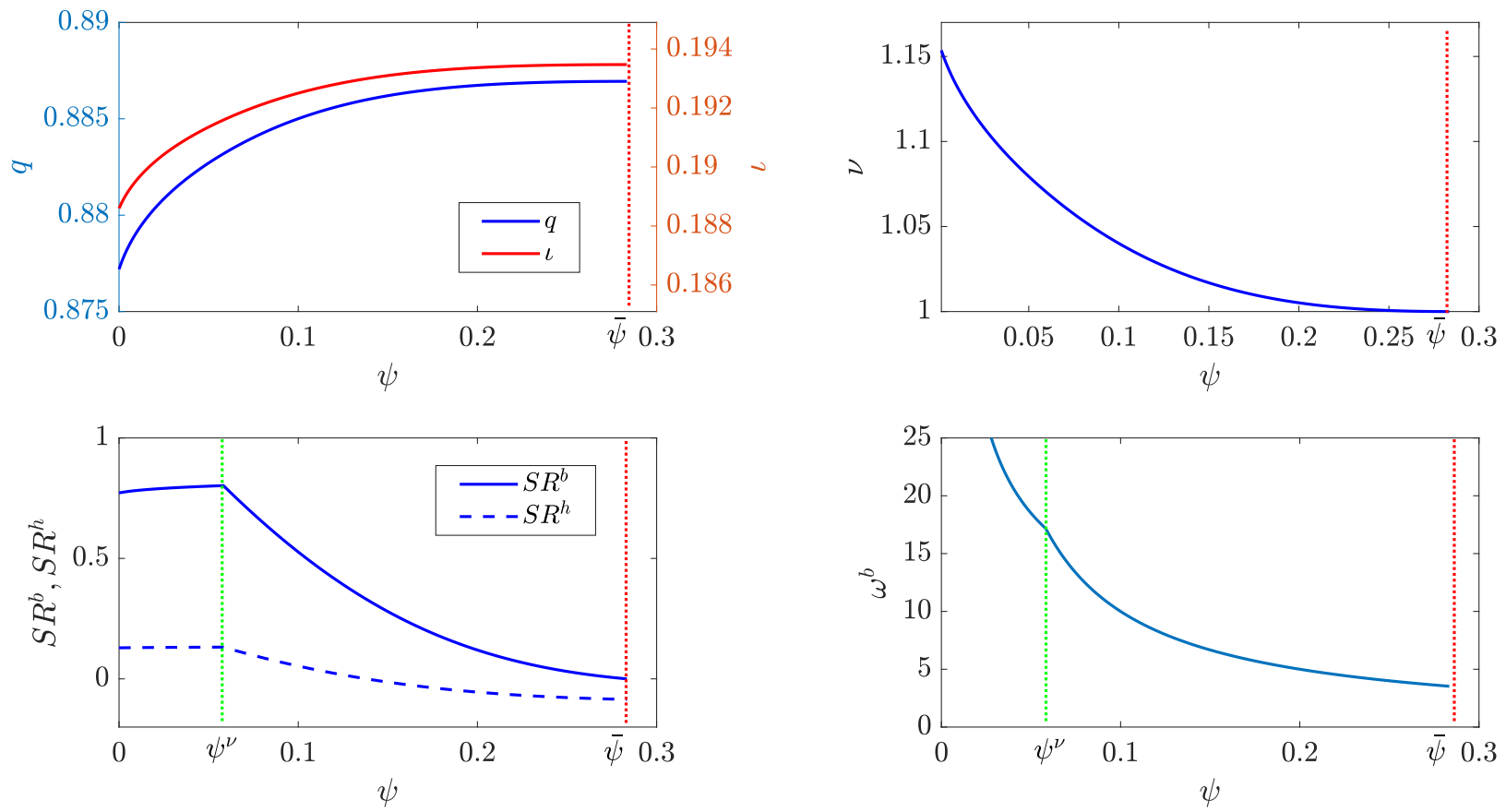

Figure 3: Top: equilibrium values of physical capital prices (blue, left), investments (red, left), and marginal value of banks' equity (top, right) as a function of the state $\psi$. Bottom left: banks' (solid) and households' (dashed, left) Sharpe ratios. Bottom right: banks' leverage. The dotted lines represent the banks dividend $\bar{\psi}$ (red) and capital allocation $\psi^{\nu}$ (green) thresholds, respectively.
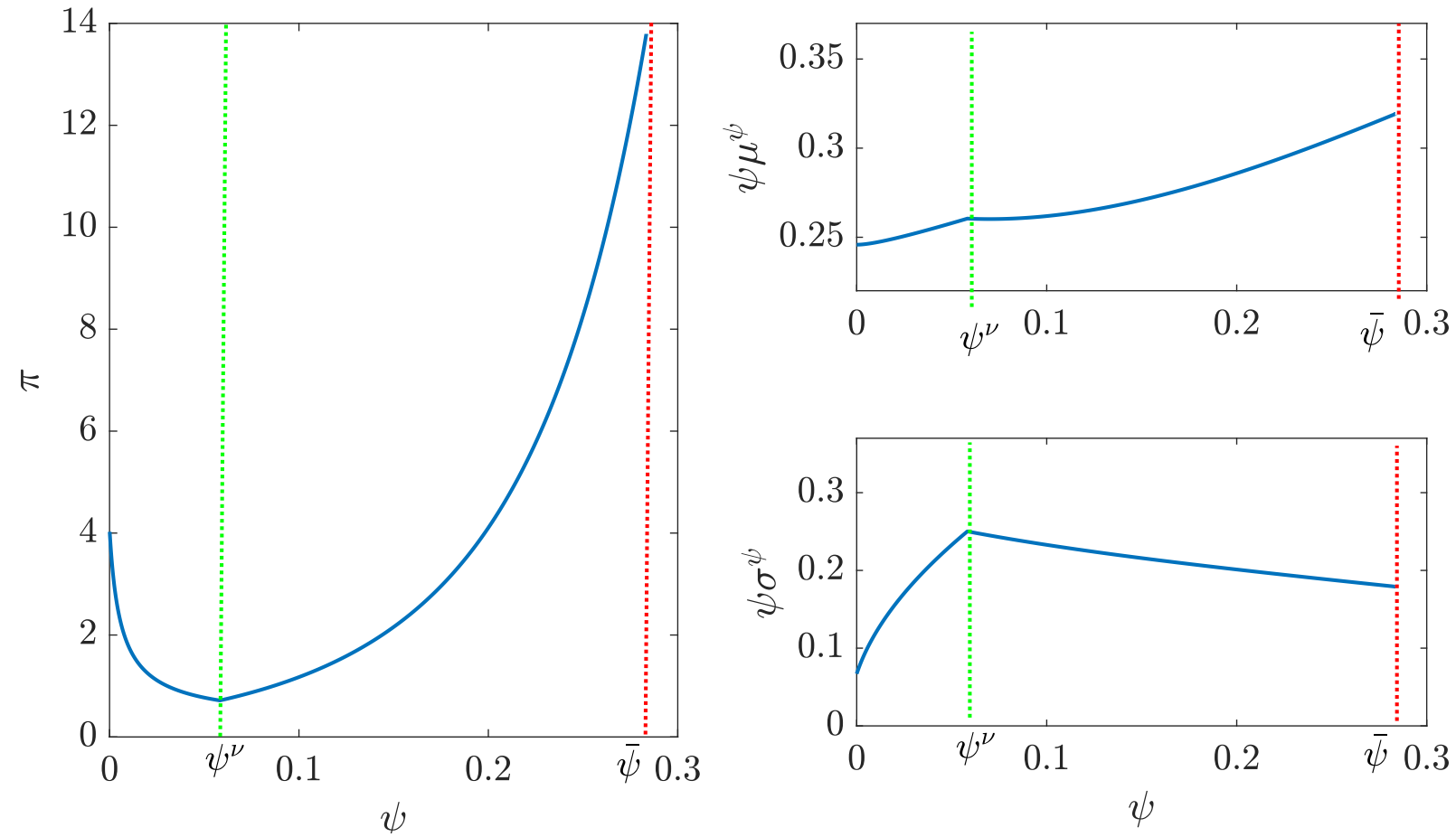

Figure 4: Stationary density (left), state drift (top, right), and diffusion (bottom, right) as function of the state $\psi$. The dotted lines represent the banks dividend $\bar{\psi}$ (red) and capital allocation $\psi^{\nu}$ (green) thresholds, respectively.

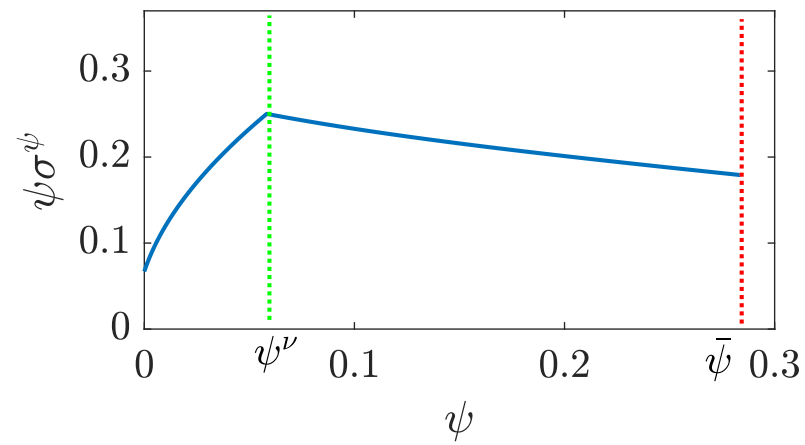


namely, the relative share of productive firms that is directly finance by the former or the latter, respectively. It follows, due to banks' efficiency gap, capital allocation jointly determine the dynamics of banks relative capitalization $\psi$, aggregate capital productivity, banks' marginal value and, in turn, market prices $\nu(\psi)$ and $q(\psi)$, that individual atomistic agents take as given. In other words, banks capital structure and relative capitalization fundamentally channel pecuniary externalities on both real and financial assets.

Overall, the value of banks' equity $\nu(\psi)$ is decreasing in banking sector relative capitalization. In other words, banks' equity is more valuable when it is scarce. This result fundamentally relates to the equilibrium leverage of banks $\omega^{b}$, their Sharpe Ratio $S R^{b}(\mathrm{SR})$, and therefore their precautionary motif. Similar to the expert agents in Brunnermeier and Sannikov (2014), the risk neutral banks of our model act as if they were risk averse. This is because when they make their portfolio (leverage) decisions, banks take into account the correlation between the marginal value of their equity and the dynamic return on their risky stakes in capital producing firms. Accordingly, as issuing new equity is to them costly, they do not leverage excessively - issue inelastically StL - unless they have enough capital to do so. In equilibrium, this means that banks are less willing to hold capital in more volatile states.

This feature of the equilibrium dynamics is particularly clear when looking at the outcomes of the numerical solution in Figure 3, that exhibit a kink at $\psi^{\nu}$. In fact, to the right hand side of the kink (capital allocation threshold), banks have enough capital to leverage out the whole capital stock from households, $k_{t}^{h}=0$, and the inequality that describes the relationship between banks' capital and leverage $\omega^{b} \leq \frac{1}{\psi}$ holds with equality. Conversely, to the left-hand side of the kink banks do not have enough capital to finance firms only by themselves. Therefore, households contribute directly (partially) to the constitution of capital producing firms and pay the associated monitoring cost $\left(k_{t}^{h}>0\right)$.

Consistently, banks' leverage and SR are higher for lower $\psi$, decreasing in banks' aggregate capitalization. Moreover, banks' SR is always higher than for households $S R^{b}>S R^{h}{ }^{18}$

As far as the price of physical capital is concerned (jointly determined with the re-

\footnotetext{
${ }^{18}$ When the "precautionary motif constraint" of banks is binding, i.e. their capital is relatively scarce, households' SR holds constant and equal to $\Gamma$ (see Figure 3, dashed line).
} 
investment rate of capital producing firms), it holds increasing and concave in $\psi$. This happens because, due to their cost advantage at monitoring capital producing firms, the investments performed through banks increases the marginal productivity of physical capital. Higher productivity originates higher prices that, given the Tobin's Q in (4), also increases the equilibrium re-investment rate $\iota$, and so the growth rate of the aggregate capital stock (Equation 2).

The increasing (decreasing) pattern of physical capital prices (banks' equity marginal value) in $\psi$ implies that there may exist a trade-off between the dis-utility of decreasing banks marginal value versus the benefits of higher prices and investments that associate to a more solid banking sector. Note that higher bank capitalization also improves households' liquidity benefits as it counters banks' precautionary motif.

As we shall see, when households and banks act in perfectly competitive markets, they do not internalize the effect of their relative capitalization over equilibrium outcomes. Therefore, there is room for the government to improve households' welfare by implementing a (bailout) reallocation policy that recapitalizes the banking sector.

Stationary density Another feature of the equilibrium that is relevant to discuss relates to the stationary density of $\psi$, henceforth denoted $\pi(\psi)$. In Figure 4 we plot the stationary density $\pi(\psi)$ (left) jointly with the drift (top, right) and diffusion (bottom, right) of banks' relative capitalization a function of the state (see Risken, 1996, for details).

Similar to the equilibrium described in Brunnermeier and Sannikov (2014), the economy spends most of the time to states where the banking sector is well capitalized. In fact, on average, the state always shift towards the upper boundary $\bar{\psi}$, where the banks pay out dividends to their shareholders. However, the state stationary density exhibits the so-called "stationary instability" (see Brunnermeier and Sannikov, 2014). In other words, when in the neighbourhood of the capital allocation threshold $\psi^{\nu}$, the economy may shift abruptly to persistently "bad" regimes of low bank capitalization, low investments, and high(er) risk premiums (see Figure 4, left). ${ }^{19}$

\footnotetext{
${ }^{19}$ It is relevant to highlight that the instability in the dynamics of $\psi$ is generated by the highly non-linear behaviour of the diffusion term $\psi \sigma^{\psi}$ that is maximal approaching the region where banks' precautionary motif constraints are binding.
} 
In the "bad" states, banks' leverage is constrained because of their precautionary motif, and they are endogenously hindered on their path toward recovery. For this reason, as banks' optimal recapitalization policy is to issue new equity to remain just above the lower threshold $\underline{\psi}=0$, a stream of adverse shocks may dampen the system in the neighbourhood of $\underline{\psi}$, where frequent equity issuances are required and volatility is high. In this perspective, a tax financed bailout may benefit social welfare.

\section{Welfare and bailout}

So far, we have exclusively considered the aggregate recapitalization flow that is given by individual banks' optimal strategies, so that households transfer resources from their net worth in order to keep their own bank solvent.

In this perspective, further questions arise spontaneously: are individual recapitalization policies also optimal from the social standpoint? If not, is there any room for government interventions?

We answer these questions by considering the possibility of an additional recapitalization policy that complements banks' individual equity issuance. The new regime is enforced by the government sector who imposes households with lump sum taxation and evenly redistributes its revenues across banks. In this term, government recapitalization can be interpreted as a bailout of the whole banking sector. The aim of bailouts is to maximize long-run (ex-ante) households' welfare.

The remainder of this section is organized as follows. First, 4.1 defines households' shortand long-run welfare. Second, 4.2 characterises the government bailout regime, outlines the assumption involved in its implementation, and explains why such a policy may be socially optimal. 


\subsection{Welfare}

Short-run (ex-post) welfare According to the results summarized in Proposition 1, it is possible to show that households' value $H$ (conditional on the state $\psi$ ) holds as

$$
H(\psi, K)=K h(\psi, 1)=\mathbb{E}_{0} \int_{0}^{\infty} e^{-\rho t} K \Theta(\psi) d t
$$

where

$$
\begin{gathered}
\Theta(\psi):=\underbrace{[A-\iota(\psi)]}_{\text {Consumption, } \Theta^{c}}-\underbrace{\left[\omega^{b}(\psi) \psi-1\right]}_{\text {Monitoring, } \Theta^{m}} \eta \underbrace{\Gamma \psi q(\psi)\left[\omega^{b}(\psi)-1\right]}_{\text {Liquidity, } \Theta^{l}} ; \\
h(\psi, 1)=q(\psi)[(1-\psi)+\nu(\psi) \psi],
\end{gathered}
$$

and $K$ and $\psi$ evolve as (2) and (23), respectively. Equation (27) can be interpreted as the short-run (or ex-post) households' welfare. ${ }^{20}$

Long-run (ex-ante) welfare In order to evaluate the effect government bailout, one may measure households' welfare ex-ante, that is, non conditional on the initial state $\psi$. We do so by integrating over $\psi \in(0, \bar{\psi}]$ the short-run welfare function $h(\psi)$ weighted by the stationary density $\pi(\psi)$. Formally, households' long-run welfare $W$ holds as follows:

$$
W:=\int_{0}^{\bar{\psi}} h(\psi) \pi(\psi) d \psi
$$

Equation (30) can be also interpreted as the households' long-run welfare since, as $t \rightarrow \infty$, the state variable $\psi$ visits every state within the support $(0, \bar{\psi}]$ with density $\pi(\psi)$.

\footnotetext{
${ }^{20}$ Households' welfare function is homogeneous of degree one in the aggregate stock of physical capital $K$. For this reason, from now on we rescale it for unitary aggregate capital stock $K=1$. Moreover, the function $h$ solves the following ODE of the second order (see also Phelan, 2016):

$$
\left\{\rho-[\Phi(\iota(q(\psi))-\delta]\} h(\psi)=\Theta(\psi)+\partial_{\psi} h(\psi) \psi\left[\mu^{\psi}+\sigma^{\psi} \sigma\right]+\frac{1}{2} \partial_{\psi \psi}^{2} h\left(\psi \sigma^{\psi}\right)^{2},\right.
$$

with boundary conditions $h(0)=\max _{\iota} \frac{A-\eta-\iota(0)}{\rho+\delta-\Phi(\iota(0)}$ and $\partial_{\psi} h(\bar{\psi})=0$. The features of the welfare function components as well as all derivations are discussed at length in Appendix G.
} 


\subsection{Bailout}

Are individual recapitalization choices also socially optimal? What is the welfare effect of bailout recapitalization?

To answer these questions, we consider the redistributive taxation imposed by the government described in Section 2.3. The government implements (and commits to) a bailout policy that redistributes resources $d T^{\pi}$ from households' wealth towards the banking sector equity. It does so conditional on reaching an exogenous default threshold $\psi \leq \psi^{\Omega}$. Moreover, similar as for issuing equity, we assume that the resources raised to bailout banks are partially depleted after the payment of administrative costs $\lambda^{G} \geq \lambda$. Accordingly, at the moment of bailout the banking sector receives $d T^{\pi}$ additional capital injection (see Equation 12), while $d T^{\pi} \lambda^{G}$ resource are instantaneously depleted.

To the purpose of our analysis, we approximate the process $d T_{t}^{\pi}$ with a deterministic function of households' holdings in StL and risky stakes in firms $D^{h}+K^{h} q=E^{h}$ (see also Equation 8):

$$
d T^{\pi}:=T^{\pi} E^{h} d t
$$

where $T^{\pi}$ is the tax rate selected by the government. The government chooses the (socially optimal) tax rate that maximises long-run households' welfare (30). Formally:

\section{Definition 1. Socially optimal tax rate - bailout}

Given the approximation in (31), conditional on an exogenous threshold $\psi \leq \psi^{\Omega}$, the government implements a bailout recapitalization policy by raising taxes from households' net worth. It does so by choosing the tax rate $T^{\pi, *}$, henceforth optimal tax rate, that maximises their long-run welfare (30):

$$
T^{\pi, *}=\arg \max _{T^{\pi}} W
$$

Once that the possibility of government bailout is accounted for, it is possible to show that the dynamics of relative banks' capitalization, henceforth $d \psi^{\Omega}$, evolves as

$$
\frac{d \psi^{\Omega}}{\psi^{\Omega}}=\frac{d \psi}{\psi}+\underbrace{\mathbb{I}_{\psi \leq \psi^{\Omega}} T^{\pi}(1-\psi)\left(\frac{1+\psi \lambda^{G}}{\psi}\right)}_{\text {Bailout term }} d t
$$


where $\mathbb{I}$ is the indicator function (the analytic derivation is in Appendix $H$ ).

We now numerically solve the model for its competitive equilibrium as it is described in Section 3 by considering the state dynamics (33) in place of (23).

Bailout: capital price vs bank marginal value To evaluate the equilibrium outcomes of government bailout, and to highlight the trade-off characterising gains and losses of households' welfare in the short- and in the long-run, Figure 5 (top) plots the price of physical capital $q(\psi)$ (left), and the marginal value of banks' capital $\nu(\psi)$ (right) before (blue, solid) and after (green, dashed) considering the bailout policy $\left(\psi^{\Omega}=0.01, T^{\pi}=0.1\right)$. The same Figure (bottom) also displays the results for households' short-run welfare $h(\psi)$ (left, see Equation 29) and stationary state density $\pi(\psi)$. To complete the picture, Figure 6 shows banks' leverage (left) and Sharpe ratios (right) before (blue, solid) and after (green, dashed) the bailout implementation. All red dotted lines highlight the upper threshold $\bar{\psi}$.

What stands out is that, for a moderate threshold $\psi^{\Omega}$, the possibility of government bailout shifts the price of physical capital $q$ upward (Figure 6, top right). This is because, when banks internalize the recapitalization policy, they respond by increasing their leverage (Figure 6, left). They do so to extract value, in expectation, from the government injection of new capital (see also Proposition 3) at the moment of bailout. It follows, a higher share of capital stock $K^{b}$ is under the direct management of the banking sector, lower monitoring costs are paid, and therefore capital is overall more productive. Higher capital price channels higer re-investment rate and, in turn, higher growth rate of aggregate capital stock (see Equation 2). ${ }^{21}$ On the other hand (Figure 5, top right panel), government bailout may reduce the marginal value of banks $\nu$, especially in those states where $\psi$ is low. The reason is that households take into account that the government may impose them to recapitalize the banks via taxation, and that a share of the resources collected would be depleted after administrative costs $\lambda^{G}$. Moreover, higher bank leverage also associates to higher risk, that each bank prices via her precautionary motif (Figure 6, right). It is relevant to stress that the negative relationship between banks bailouts and marginal value does not necessarily

\footnotetext{
${ }^{21}$ Remind that investments performed through banks is more productive due to their cost advantage at monitoring firms, while the re-investment rate $\iota$ relates to capital prices by the Tobin's Q relationship given by Equation (4).
} 
imply the same for the market value of banks. In fact, the bailout may increase the average banks' relative capitalization as well as the book value of their equity by its positive effect (pecuniary externality) on $q$.

All in all, we find that considering bailout recapitalization policies may reduces households' welfare in the short-run (Figure 5, bottom left), as the welfare loss due to lower banks marginal value dominates the gain in terms of capital price. However, if we look at the effect of the bailout in the long-run (Figure 5, bottom right), we notice that, although the perspective of a bailout may exacerbate the instability implicit in the stationary density $\pi(\psi)$ (higher density in both the extremities of the right and left-hand side tails of the distribution), it may also increase the likelihood of transition through "good" states while reducing that of "bad" ones. In this perspective, there exists a trade-off between the short run costs of recapitalization and the long-run benefit of a valuable reallocation of resources. This result suggests that the households may benefit from a tax-financed recapitalization policy (bailout).

The trade-off The trade-off that characterises the bailout policy boils down to the joint effect of two pecuniary externalities. On the one hand, the potential benefits are rooted in the allocation of physical capital between banks' equity and households' direct purchase of firms issued risky claims (higher physical capital price $q(\psi)$ ). On the other hand, the potential losses associate to a marginally less valuable banking sector due to the possibility of bailout (lower marginal value of banks, or equity price, $\nu(\psi)$ ).

This mechanism can be better visualized by re-writing households' long-run welfare as a sum of the (expected) market value of banks plus the residual (expected) "bail-out-able" net worth:

$$
W \propto \underbrace{\mathbb{E}^{\pi}[q(\psi) \nu(\psi) \psi]}_{\text {Bank value term }}+\underbrace{\mathbb{E}^{\pi}[q(\psi)(1-\psi)]}_{\text {"Bail-out-able" wealth term }},
$$

where $\mathbb{E}^{\pi}$ is the expected value taken with respect to the stationary density $\pi(\psi)$. According to Definition 1, the trade-off that associates to the optimal tax rate $T^{\pi, *}$ can be summarised 

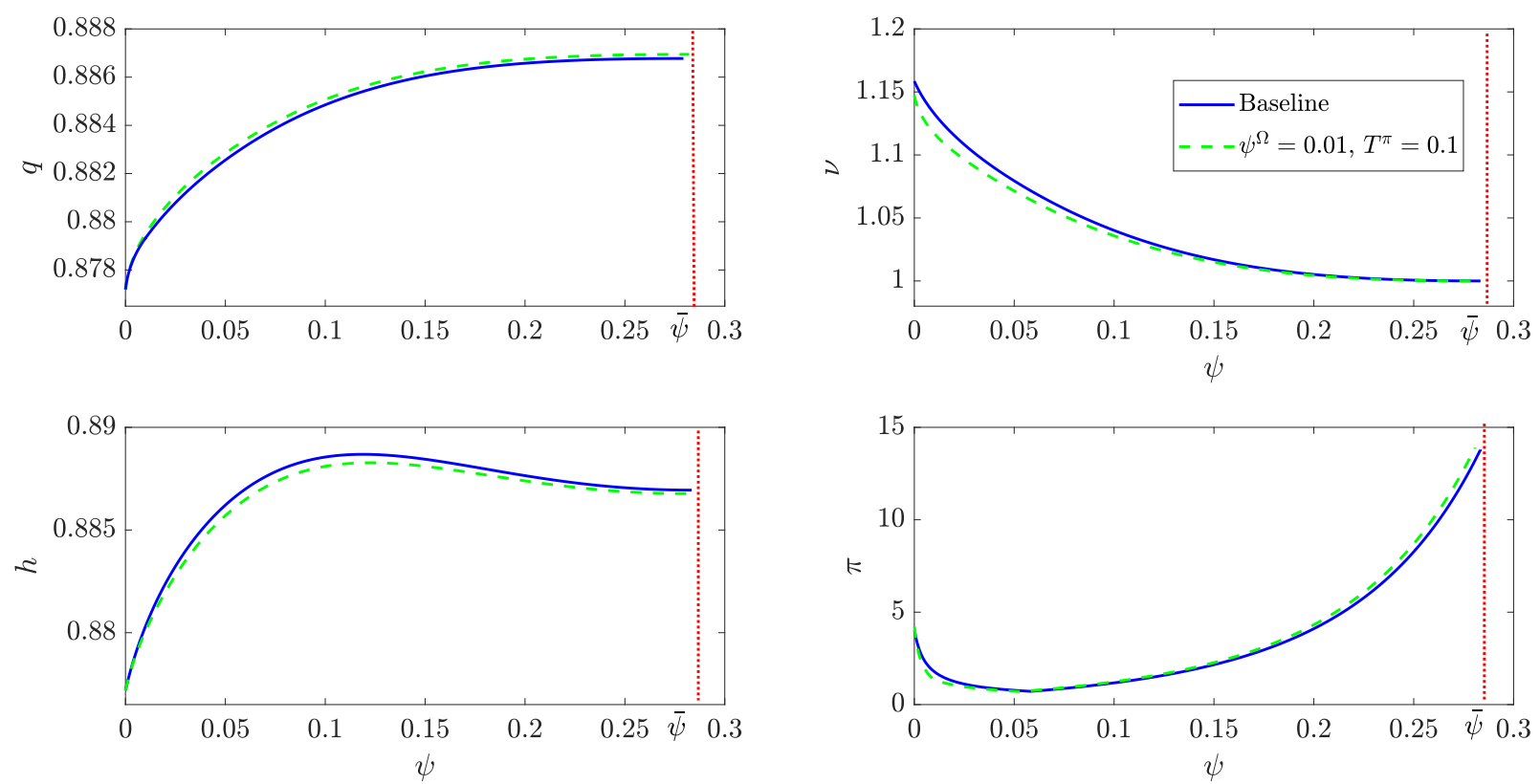

Figure 5: Top: price of physical capital (left), and marginal value of banks' capital (right) before (blue, solid) and after (green, dashed) considering the bailout policy. Bottom: households' shortrun welfare (left) and stationary state density $\pi(\psi)$. In red dotted line in all panels represent the upper threshold $\bar{\psi}$.
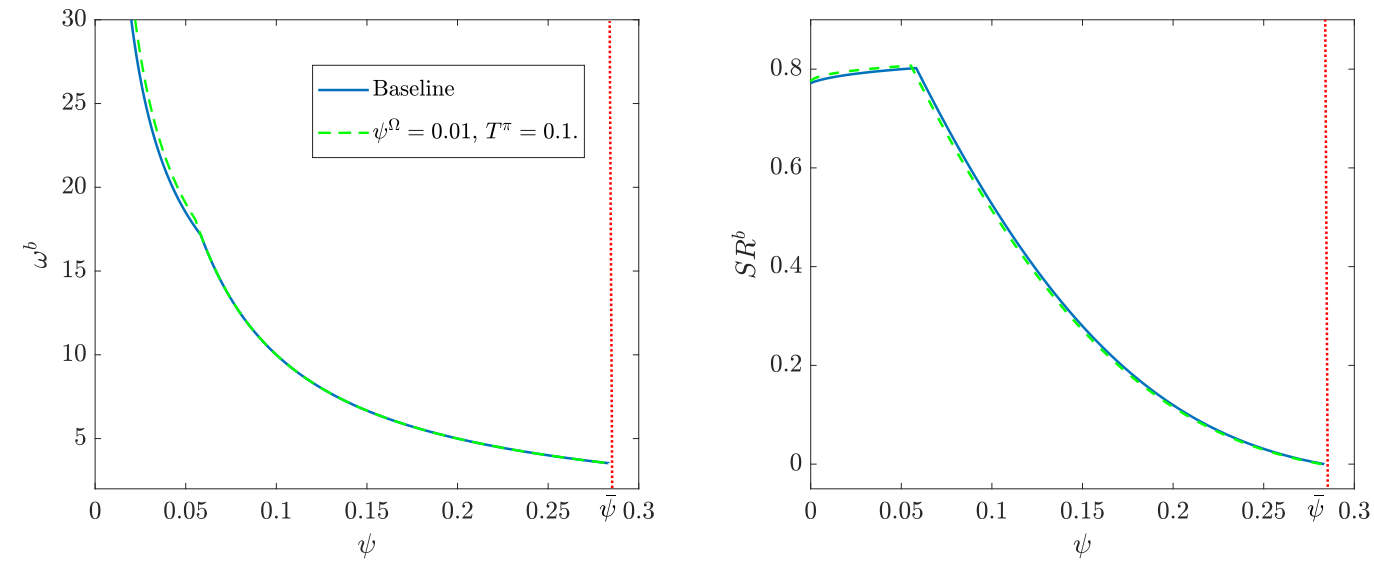

Figure 6: Banks' leverage (left) and Sharpe ratios (right) before (blue, solid) and after (green, dashed) the bailout implementation. The red dotted lines highlight the upper threshold $\bar{\psi}$. 


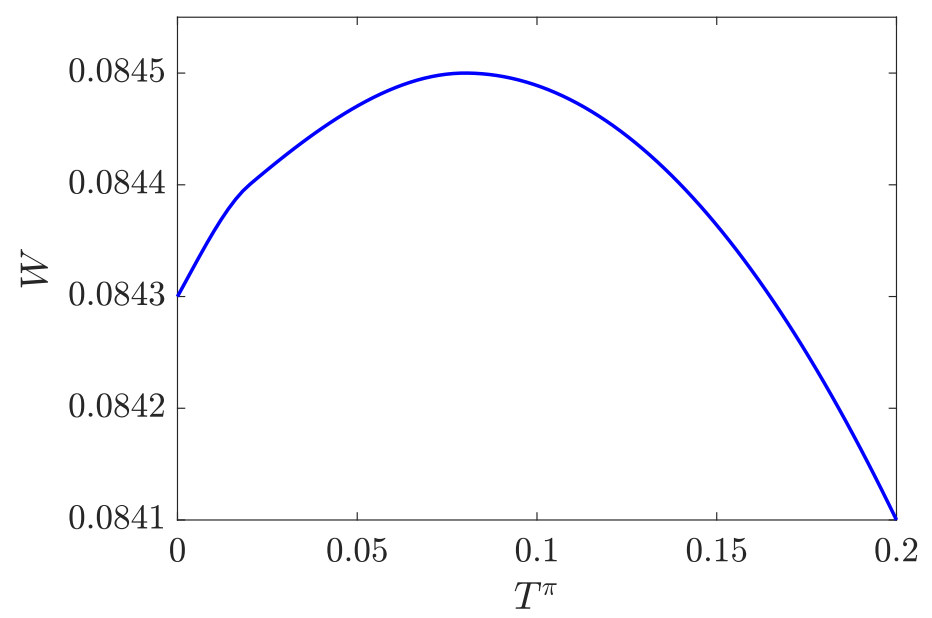

Figure 7: Households' long-run welfare as a function of the tax rate $T^{\pi}$.

by the following FOC of (34):

$$
\partial_{T^{\pi}} W=0 \Rightarrow \underbrace{\partial_{T^{\pi}} \mathbb{E}^{\pi}[q(\psi) \psi \nu(\psi)]}_{\text {Expected bank value gain }}=\underbrace{-\partial_{T^{\pi}} \mathbb{E}^{\pi}[q(\psi)(1-\psi)]}_{\text {Expected "Bail-out-able" wealth loss }} .
$$

The meaning of Equation (35) is that, at the optimum, the expected marginal loss in households" "bail-out-able" wealth due to the bailout must be compensated by the expected marginal gain in terms of banks' market value. Therefore, there is room for a welfare improving bailout as long as the benefit of reallocating resources to the banking sector, the so-called "value effect", dominates (Cordella and Yeyati, 2003).

To conclude, Figure 7 plots the long-run welfare of the households as a function of the $\operatorname{tax}$ rate $T^{\pi}$ for our baseline parametric specification. Overall, our numerical results suggest that, conditional to a relatively low default threshold $\psi^{\Omega}$, a moderate tax rate $T^{\pi, *} \approx 0.08$ maximises long-run households' welfare.

Due to the extremely stylized nature of our model, its quantitative implications are not to be taken by the book. However, going beyond the figures, our results provide a few important takeaways concerning the mechanism that interlinks bank resolution regimes to their macroeconomic outcomes. 


\section{Conclusions}

This paper develops a dynamic general equilibrium model of a productive economy with a banking sector and financial frictions. The model provides a novel insight on the interconnection between banks recapitalization policies, macroeconomic dynamics, and households' welfare in the long-run. More specifically, it characterises such a relationship as the joint effect of the pecuniary externalities of the banking sector aggregate capitalization.

The marginal value of banks' equity, that depends on the banking sector relative capitalization, is the core determinant of their dividend payout, individual recapitalization, and leverage strategies. A government bailout reallocating capital from households' wealth to banks' equity influences the latter's value, therefore affecting banks' optimal strategies and capital structure. In a model where banks provide the real economy with capital services, their risk taking capacity fundamentally affects the allocation of capital and, as such, its overall productivity. Accordingly, banking sector relative capitalization determines the price of physical capital and, in turn, firms' investments. A government bailout regime may im-

prove the capital allocation in "bad" states, where their capitalization is scarce, therefore improving the overall performance of the economy.

In a perfectly competitive environment, heterogeneous - atomistic - economic actors may fail at internalizing those externalities. Therefore, the choices that hold as optimal from their individual perspective may not be so from the social standpoint, and there may be room for welfare improving capital reallocation policies such as a bailout.

\section{References}

Acharya, V. and T. Yorulmazer (2007). Cash-in-the-market pricing and optimal resolution of bank failures. The Review of Financial Studies 21 (6), 2705-2742.

Adrian, T., E. Etula, and T. Muir (2014). Financial intermediaries and the cross-section of asset returns. The Journal of Finance 69(6), 2557-2596.

Barucci, E., T. Colozza, and C. Milani (2019). The effect of bank bail-outs in the EU. Journal of International Money and Finance, Forthcoming. 
Beck, T., D. Radev, and I. Schnabel (2020). Bank Resolution Regimes and Systemic Risk. Working paper.

Berger, A., N. Himmelberg, C. P. Roman, and S. Tsyplakov (2019). Bank bailouts, bail-ins, or no regulatory intervention? a dynamic model and empirical tests of optimal regulation. Working paper.

Bernanke, B. (January 13, 2009). The crisis and the policy response. Stamp Lecture, London School of Economics.

Bernanke, B., M. Gertler, and S. Gilchrist (1999). The financial accelerator in a quantitative business cycle framework. Handbook of Macroeconomics 1, 1341-1393.

Brunnermeier, M. and Y. Sannikov (2014). A macroeconomic model with a financial sector. The American Economic Review 104(2), 379-421.

Brunnermeier, M. and Y. Sannikov (2016). The I theory of money. National Bureau of Economic Research w22533.

Butler, A., G. Grullon, and J. Weston (2005). Stock market liquidity and the cost of issuing equity. Journal of Financial and Quantitative Analysis 40(2), 331-348.

Caprio, G. and D. Klingebiel (1996). Bank insolvency: bad luck, bad policy, or bad banking? Annual World Bank conference on development economics 79.

Cochrane, J. (2017). Macro-finance. Review of Finance 21(3), 945-985.

Commission, E. (April 2019). Eurostat supplementary table for reporting government interventions to support financial institutions. Technical report, Eurostat. Can be found at https://ec.europa.eu/eurostat/documents/1015035/9720710/Background-note-on-govinterventions-Apr-2019.pdf/3c91ed77-504b-46e3-8ecb-de1bed673c6d.

Cordella, T. and E. L. Yeyati (2003). Bank bailouts: moral hazard vs. value effect. Journal of Financial Intermediation 12(4), 300-330.

Diamond, D. W. (1984). Financial intermediation and delegated monitoring. The review of economic studies 51(3), 393-414. 
Dindo, P., A. Modena, and L. Pelizzon (2019). Risk pooling, leverage, and the business cycle. University Ca' Foscari of Venice, Dept. of Economics Research Paper Series 21.

Flannery, M. J. (1994). Debt maturity and the deadweight cost of leverage: Optimally financing banking firms. The American economic review 84(1), 320-331.

Gale, D., A. Gamba, and M. Lucchetta (2018). Dynamic bank capital regulation in equilibrium. WBS Finance Group Research Paper.

Ghote, A. V. D. (2020). Interactions and coordination between monetary and macroprudential policies. American Economic Journal: Macroeconomics (Forthcoming).

Gorton, G. and L. Huang (2004). Liquidity, efficiency, and bank bailouts. American Economic Review 94(3), 455-483.

Gropp, H., H. Hakenes, and I. Schnabel (2010). Competition, risk-shifting, and public bailout policies. The Review of Financial Studies 24 (6), 2084-2120.

He, Z. and A. Krishnamurthy (2011). A model of capital and crises. The Review of Economic Studies 79(2), 735-777.

He, Z. and A. Krishnamurthy (2013). Intermediary asset pricing. The American Economic Review 103(2), 732-770.

He, Z. and A. Krishnamurthy (2019). A macroeconomic framework for quantifying systemic risk. American Economic Journal: Macroeconomics. Forthcoming.

Hennessy, C. (2004). Tobin's q, debt overhang, and investment. The Journal of Finance $59(4), 1717-1742$.

Hilscher, J. and A. Raviv (2014). Bank stability and market discipline: The effect of contingent capital on risk taking and default probability. Journal of Corporate Finance 29, $542-560$.

Hoggarth, G., R. Reis, and V. Saporta (2002). Costs of banking system instability: some empirical evidence. Journal of Banking \& Finance 26(5), 825-855. 
Homar, T. and S. van Wijnbergen (2017). Bank recapitalization and economic recovery after financial crises. Journal of Financial Intermediation 32, 16-28.

Honohan, P. and D. Klingebiel (2000). Controlling the fiscal costs of banking crises. The World Bank.

Hryckiewicz, A. (2014). What do we know about the impact of government interventions in the banking sector? an assessment of various bailout programs on bank behavior. Journal of Banking $\&$ Finance 46, 246-265.

Hugonnier, J. and E. Morellec (2017). Bank capital, liquid reserves, and insolvency risk. Journal of Financial Economics 125(2), 266-285.

Klimenko, N., S. Pfeil, J.-C. Rochet, and G. D. Nicolo (2016). Aggregate bank capital and credit dynamics. Swiss Finance Institute Research Paper, 19-42.

Lambrecht, B. and A. Tse (2019). Liquidation, bailout, and bail-in: Insolvency resolution mechanisms and bank lending. Working paper.

Leanza, L., A. Sbuelz, and A. Tarelli (2019). Bail-in vs bail-out: Bank resolution and liability structure. Available at SSRN 3330032.

Leland, H. (1994). Bond prices, yield spreads, and optimal capital structure with default risk. No. RPF-240, University of California at Berkeley,.

Løkka, A. and M. Zervos (2008). Optimal dividend and issuance of equity policies in the presence of proportional costs. Insurance: Mathematics and Economics 42(3), 954-961.

Maggiori, M. (2017). Financial intermediation, international risk sharing, and reserve currencies. American Economic Review 107(10), 3038-71.

Mendicino, C., K. Nikolov, J. Suarez, and D. Supera (2019). Bank capital in the short and in the long run. Journal of Monetary Economics Forthcoming.

Nicolo, G. D., A. Gamba, and M. Lucchetta (2014). Microprudential regulation in a dynamic model of banking. The Review of Financial Studies 27(7), 2097-2138. 
Nuno, C. and H. Rey (2017). Financial cycles with heterogeneous intermediaries. National Bureau of Economic Research, No. w23245.

Peura, S. and J. Keppo (2006). Optimal bank capital with costly recapitalization. The Journal of Business $79(4), 2163-2201$.

Phelan, G. (2016). Financial intermediation, leverage, and macroeconomic instability. American Economic Journal: Macroeconomics 8(4), 199-224.

Philippon, T. and P. Schnabl (2013). Efficient recapitalization. The Journal of Finance $68(1), 1-42$.

Risken, H. (1996). The Fokker-planck Equation, Volume 63-95. Springer, Berlin.

Sandri, D. and F. Valencia (2013). Financial crises and recapitalizations. Journal of Money, Credit and Banking 45(s2), 59-86.

Sarin, N. and L. Summers (2016). Have big banks gotten safer? Brookings Institution.

Stein, J. (2012). Monetary policy as financial stability regulation. The Quarterly Journal of Economics 127(1), 57-95.

Stokey, N. L. (2009). The Economics of Inaction: Stochastic Control models with fixed costs. Princeton University Press.

Tirole, J. (2010). The theory of corporate finance. Princeton University Press. 


\section{Online Appendix}

\section{A Banks, financial intermediaries, and IC constraints}

This Appendix outlines a generalisation of the baseline model described in Section 2 that accounts for for the Limited Enforcement Problem (LCP) that may arise between households and banks when the latter are managed by financial intermediaries.

Let us assume that banks are owned by households but managed by financial intermediaries. The latter may finance banks assets either via their equity or by issuing risk-free StLs. Similar to the limited enforcement problem outlined in Bernanke et al. (1999) (see also Ghote, 2020, for a similar setting in continuous-time), immediately after raising StL intermediaries can choose to liquidate banks total assets net of an exogenous haircut $\chi \in(0,1)$ that constitutes an additional financial friction of the economy.

Provided that the remainder of the liquidated assets $(1-\chi)$ is not sufficient to redeem their principal (i.e. banks market value, henceforth simply "value") in full, intermediaries would have the incentive to default on the StLs. In order to prevent them for exploiting the diversion strategy, it must hold that the value of the bank under their management holds greater than (or equal to) the haircut value of the liquidated assets. Note that, for the limited enforcement friction to be meaningful, one must assume that each intermediary is owned by a single household and that she borrows only from households other than their direct owner (on this point, see also Maggiori, 2017).

Formally, let $J_{t}^{b}$ denote the value of a bank with equity book value $e_{t}^{b}$ at time $t$ and $\omega_{t}^{b}$ be her leverage. Under the optimal policy, bank's total assets $a_{t}^{b}$ can be expressed as $a_{t}^{b}=\omega_{t}^{b} e_{t}^{b}$, and the IC constraint holds as:

$$
a_{t}^{b}(1-\chi) \leq J_{t}^{b}
$$

for each $t \in[0, \infty)$. Note that, when banks' value $J_{t}^{b}$ can be expressed as a linear function of the book value of her equity, that is, $J_{t}^{b}=\nu_{t}^{b} e_{t}^{b}$ (as we shall see, this is going to be the case of this paper, where $\nu_{t}$ represents the marginal value of banks' equity), then the IC constraint 
in Equation (36) implies an endogenous constraint over banks' leverage:

$$
\omega_{t}^{b} \leq \frac{\nu_{t}}{1-\chi}
$$

that is, banks leverage must hold smaller than or equal to a multiple $\frac{1}{1-\chi}$ of the marginal value of their equity.

\section{B Banks' efficiency edge}

Similar to Ghote (2020), this Appendix provides a micro-foundation - rationalization - of banks cost advantage at monitoring output producing firms that generates what we defined as efficiency edge $\eta=\eta^{h}-\eta^{b}$.

Let the productivity rate across output producing firms $A$ be idiosyncratic and stochastic. In particular, it may take high and low values $A^{h}$ and $A^{l}$ with probabilities $p$ and $1-p$, respectively. By exerting costly effort $\varepsilon$ per unit of rent capital, output producing firms can increase the probability $p$ to $p^{\varepsilon}>p>0$. Then, as long as

$$
A^{h} p^{\epsilon}+A^{l}\left(1-p^{\epsilon}\right)-\varepsilon \geq A^{h} p+A^{l}(1-p)
$$

there exists a moral hazard problem between productive firms and their capital supplier, that is, their shareholders (here households or banks). The problem can be tackled either directly, via costly monitoring, or indirectly implementing an optimal contract.

(Direct) Costly monitoring Costly monitoring is so that households and banks pay a

fixed cost $\left(\eta^{h}\right.$ and $\eta^{b}$, respectively) for each unit of capital supplied, that is, out of firms dividend payouts. The monitoring activity is assumed to be efficient and prevents output producing firms from not exerting effort.

(Indirect) Optimal contract Alternatively, households and bank may decide to write an incentive compatible contract conditional on the productivity realization. The contract is so that the shareholders commit to pay a premium $x$ to the producers in order to remunerate 
their effort. Without loss of generality, by setting $A^{l}=0$, the premium $x$ must be so that

$$
x p^{\varepsilon}-\varepsilon=x p \Rightarrow x=\frac{\varepsilon}{p^{\varepsilon}-p} .
$$

Finally, we assume that $\eta^{h}<\frac{\varepsilon}{p^{\varepsilon}-p}$, so that households (and banks, because $\eta^{h}>\eta^{b}$ ) always decide to pay the monitoring cost rather than settling the incentive compatible contract.

\section{Bank recapitalization - optimal stopping time}

Let us fix an initial condition on bank $b$ 's book value $e^{b}=e_{0}$. Henceforth, we omit redundant sup and subscripts for sake of clear notation.

Also, let $\tau$ be the first time that the bank equity process reaches $(-\infty, 0)$, i.e. the bank decides not to issue equity and goes bankrupt. Moreover, let $J$ be the solution of (11) with complementary condition (14).

By definition, the bank's continuation value satisfies

$$
J\left(e_{0}\right)=\int_{0}^{\tau \wedge t} e^{-\rho t}[\left(d \Delta_{t}-(1+\lambda) d \Pi_{t}\right]+\underbrace{e^{-\rho(t \wedge \tau)} J\left(e_{t \wedge \tau}\right)}_{\text {Continuation }} .
$$

By taking the differential $d\left(J(e) e^{-\rho t}\right)$, applying Itô's Lemma, and integrating over $(0, t \wedge$ $\tau$ ), the following relationship between the dynamics of bank's equity (book value) and continuation value holds:

$$
\begin{array}{r}
e^{-\rho(t \wedge \tau)} J\left(e_{t \wedge \tau}\right)=J\left(e_{0}\right)+\int_{0}^{t \wedge \tau} e^{-\rho s}\left[-\rho J\left(e_{s}\right)+\mu^{e} e \partial_{e} J\left(e_{s}\right)+\frac{1}{2}\left(e \sigma^{e}\right)^{2} \partial_{e e}^{2} J\left(e_{s}\right)\right] d s+ \\
+\int_{0}^{t \wedge \tau} e^{-\rho s} e \sigma^{e} \partial_{e} J\left(e_{s}\right) d W_{t}-\int_{0}^{t \wedge \tau} \partial_{e} J\left(e_{s}\right) e^{-\rho s} d \Delta_{s}+\int_{0}^{t \wedge \tau} \partial_{e} J\left(e_{s}\right) e^{-\rho s} d \Pi_{s}
\end{array}
$$

where $\mu^{e}$ and $\sigma^{e}$ represents the drift and diffusion of the stochastic process that describes the dynamics of bank's $b$ equity $\frac{d\left(e^{b}\right)}{e^{b}}$.

Then, by matching (37) and (38), we obtain the following expression that relates bank's 
$b$ market value $J$ to the dynamics of her book value $e^{b}$ :

$$
\begin{aligned}
\int_{0}^{\tau \wedge t} e^{-\rho t}\left[\left(d \Delta_{t}-(1+\lambda) d \Pi_{t}\right] d t \leq\right. & \\
& -e^{-\rho(t \wedge \tau)} J\left(e_{t \wedge \tau}\right)+\int_{0}^{\tau \wedge t} e^{-\rho t}[\underbrace{1-\partial_{e} J\left(e_{s}\right)}_{\leq 0}] d \Delta_{t}+ \\
& +\int_{0}^{\tau \wedge t} e^{-\rho t}[\underbrace{\partial_{e} J\left(e_{s}\right)-(1+\lambda)}_{\leq 0}] d \Pi_{t}+J\left(e_{0}\right)+ \\
+\int_{0}^{t \wedge \tau} e^{-\rho s}[\underbrace{-\rho J\left(e_{s}\right)+\mu^{e} e \partial_{e} J\left(e_{s}\right)+\frac{1}{2}\left(e \sigma^{e}\right)^{2} \partial_{e e}^{2} J\left(e_{s}\right)}_{=0}] d s+ & +\int_{0}^{t \wedge \tau} e^{-\rho s} e \sigma^{e} \partial_{e} J\left(e_{s}\right) d W_{t} .
\end{aligned}
$$

The third term of the right-hand side of (39) is the bank's HJBE and, by standard optimal control theory, always holds with equality over the support $\left[0, e^{\max }\right]$. Conversely, the second and third term always equal zero when the bank does neither pay dividends nor issue equity $(d \Delta=0$ and/or $d \Pi=0)$, it is negative otherwise (remind that bank's marginal value is decreasing in her capitalization $\left.\partial_{e} V\left(e^{\max }\right) \leq \partial_{e} J(e) \leq \partial_{e} V(0)\right)$.

It follows that, when $\lambda<\infty$, then Inequality (39) is well defined, it is convenient for the bank to issue new equity, and her value $J$ is maximal when

$$
\begin{cases}d \Delta(e)>0 \Longleftrightarrow \partial_{e} V(e)=1, & e=e^{\max } ; \\ d \Pi(e)>0 \Longleftrightarrow \partial_{e} V(0)=1+\lambda, & e=0 .\end{cases}
$$

and (39) holds with equality $\forall e \in\left[0, e^{\max }\right]$. In such a case, the process $d e^{b}$ is reflected at 0 and $e^{\max }$, and does not assume values in $(-\infty, 0) \cup\left(e^{\max }, \infty\right)$. Accordingly, $\tau=\infty$ and (39) reduces to

$$
\begin{aligned}
\lim _{t \rightarrow \infty} \int_{0}^{\tau \wedge t} e^{-\rho t}\left[\left(d \Delta_{t}-(1+\lambda) d \Pi_{t}\right] d t=-\lim _{t \rightarrow \infty} e^{-\rho(t \wedge \tau)} J\left(e_{t \wedge \tau}\right)+\right. & \\
& \quad+\lim _{t \rightarrow \infty} \int_{0}^{t \wedge \tau} e^{-\rho s} e \sigma^{e} \partial_{e} J\left(e_{s}\right) d W_{t}+V\left(e_{0}\right) .
\end{aligned}
$$


By taking expected value at time $t=0$ and considering the transversality condition

$$
\lim _{t \rightarrow \infty} \mathbb{E}_{0} e^{-\rho(t \wedge \tau)} J\left(e_{t \wedge \tau}\right)=0
$$

it holds that

$$
J\left(e_{0}\right)=\mathbb{E}_{0} \int_{0}^{\infty} e^{-\rho t}\left[\left(d \Delta_{t}-(1+\lambda) d \Pi_{t}\right] d t\right.
$$

\section{The economy with no banks}

The natural benchmark case of our analysis is the economy with no banks, where $\psi=$

$\mu^{\psi}=\sigma^{\psi}=0$, and there are is no recapitalization of the banking sector. In the economy with no banks the price $q$ and the re-investment rate $\iota$ are constant and equal

$$
\begin{gathered}
\iota=\frac{q-1}{\theta}, \\
q=\max _{\iota} \frac{A-\eta-\iota}{\rho+\delta-\Phi(\iota)} .
\end{gathered}
$$

Thus, the aggregate consumption equals $C^{h}=K[A-\iota-\eta]$, and its dynamics follows a GBM as well as the one of physical capital

$$
\frac{d C^{h}}{C^{h}}=\frac{d K}{K}=\Phi(\iota) d t+\sigma d W_{t}
$$

\section{E Comparative statics}

Figure 8 plots the equilibrium marginal value of banks' equity $\nu$ with respect to low (blue) and high (green) parametric values for the banking premium $\eta$ (top, left), the recapitalization friction $\lambda$ (top, right), the exogenous volatility component $\sigma$ (bottom, left), and the friction on physical capital $\theta$ (bottom, right) over the interval $\psi \in(0, \bar{\psi}]$.

First, a higher banking premium $\bar{\eta}$ fundamentally increases the marginal value of the banking sector. Accordingly, it shifts forward the upper threshold $\bar{\psi}$ at which dividends are paid out. As the households extract more value from the banks having a greater capitaliz- 

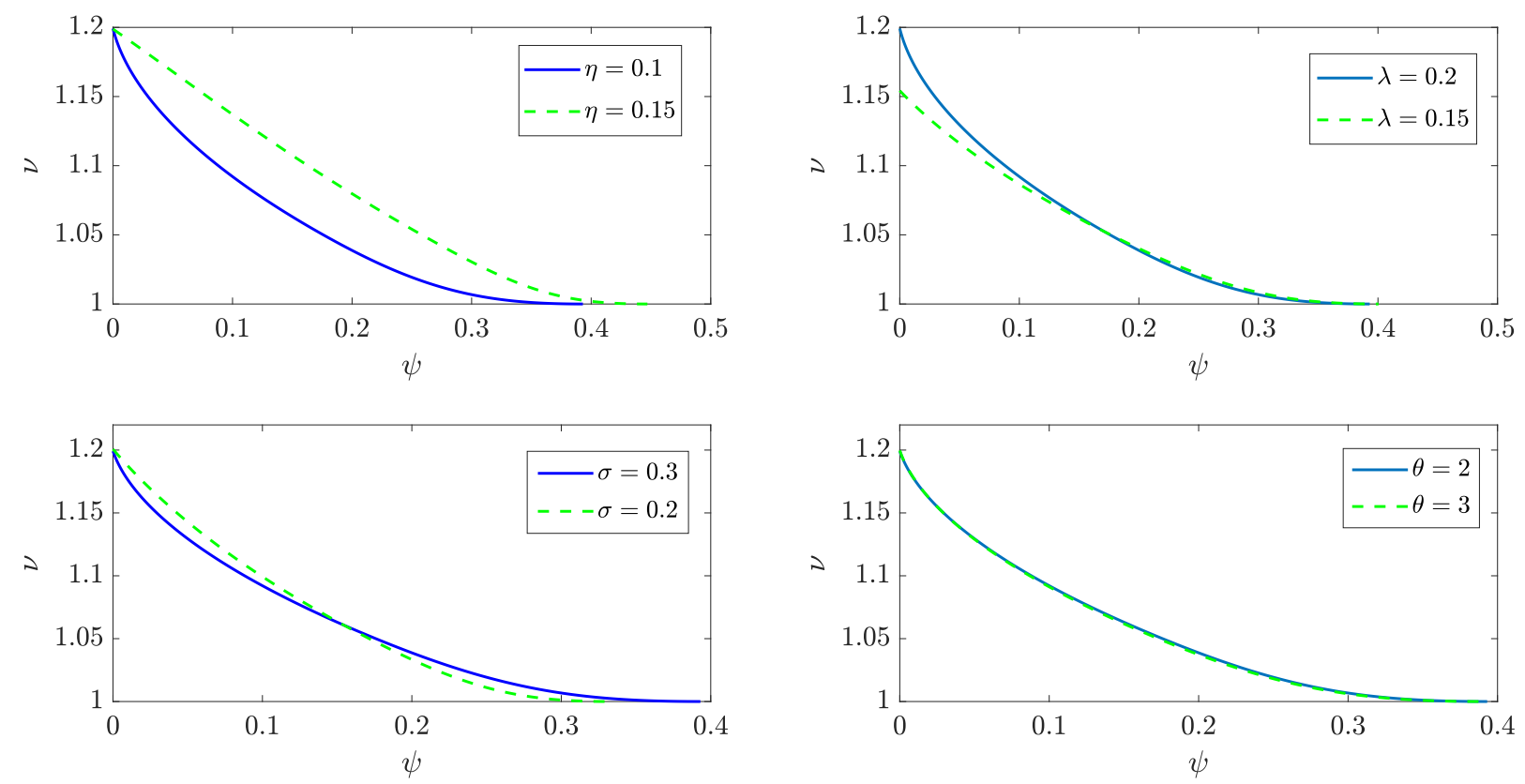

Figure 8: Comparative statics of banks' equity marginal value as a function of the key parameters of the model: banking premium $\eta$ (top, left), recapitalization friction $\lambda$ (top, right), exogenous systematic volatility $\sigma$ (bottom, left), and physical capital friction $\theta$ (bottom, right).

ation, they are willing to wait longer before receiving dividend payouts. This is because a higher premium corresponds to "more profitable" monitoring services supplied by the banking sector with respect to households.

Second, increasing the exogenous volatility parameter $\sigma$ had an ambiguous effect on the banks' value depending on the level of $\psi$. In fact, it increases banks marginal value for lower capitalization, it decreases it for higher ones. All in all, higher systematic volatility increases the equilibrium capital buffer held by the banking sector, i.e. it $\bar{\psi}$ shifts to the right-

Third, similarly as for $\sigma$, higher recapitalization friction $\lambda$ has ambiguous effects over $\nu$ : higher $\lambda$ increases the marginal value of banks for lower values of $\psi$ while it increases it for higher ones. Overall, according to our numerical results the level of $\lambda$ does not change fundamentally the dividend threshold $\bar{\psi}$.

Fourth, an increase in the technological illiquidity parameter $\theta$ does not fundamentally change banks' equity marginal value. 


\section{F Proofs}

\section{F.1 Households' problem}

For sake of clear notation, we omit all time subscripts. By standard continuous-time stochastic control methods, households' strategies satisfy the following:

$$
0=\sup _{d^{h}}\left\{\Gamma\left(d^{h}\right)+(r-\rho) d^{h}\right\}+\sup _{k^{h}}\left\{k^{h}\left(\frac{1}{d t} \mathbb{E} d R^{h}-\rho\right)\right\}+\mathbb{E}\left[d B^{b}\right]+d T
$$

where $d B_{t}^{b}:=d \Delta_{t}^{b}-(1+\lambda) d \Pi_{t}^{b}$ denotes the dynamics of bank $b$ value, $d R^{h}$ the return on households' risky assets, and $d T$ the government tax transfer. Therefore, the FOCs for capital holdings and banks' short-term liabilities hold as

$$
\frac{1}{d t} \mathbb{E} d R^{h} \leq \mu-\frac{\eta}{q}=\rho
$$

with equality when $k^{h}>0$, and

$$
r=\rho-\partial_{d} \Gamma\left(d^{b}\right)
$$

whereas the FOC for consumption $c^{h}$ is indeterminate. As we shall see, it will be pinned down by market clearing conditions.

\section{F.2 Equilibrium}

The formal statement of the competitive equilibrium reads as follows:

\section{Definition 2. Competitive equilibrium}

Conditional on an initial allocation of capita between banks' equity and households $\psi_{0}$, an equilibrium is an adapted stochastic process that maps histories of exogenous systematic shocks $\left\{d W_{t}\right\}$ to prices $\left\{q_{t}, \nu_{t}\right\}$, return on risky claims $\left\{d R_{t}\right\}$, risk-free interest rate on shortterm bank liabilities $\left\{r_{t}\right\}$, production choices $\left\{K_{t}, \iota_{t}\right\}$, consumption choices $\left\{c_{t}^{h}: h \in \mathbb{H}\right\}$, al-

locations $\left\{d_{t}^{i}, k_{t}^{i}: i \in\{\mathbb{H}, \mathbb{B}\}\right\}$, as well as dividend and recapitalization strategies $\left\{d \delta_{t}^{b}, d \pi_{t}^{b}: b \in \mathbb{B}\right\}$ such that: 
1. The firms maximise their profits:

$$
\left\{K_{t}, \iota_{t}\right\}=\arg \max _{\left\{K_{t}, \iota_{t}\right\} \in T}\left\{\mathbb{E}_{t}\left[V_{s} e^{-\int_{t}^{s} r_{u} d u}\right]-K_{t} q_{t}\right\}
$$

where $V_{s}$ are the firms revenues at between $t$ and $s=t+d t$ at time $s$.

2. The household $h \in \mathbb{H}$ maximise their utility:

$$
\left\{c_{t}^{h}, d_{t}^{h}, k_{t}^{h}\right\} \in \arg \sup _{\left\{c_{t}^{h}, d_{t}^{h}, k_{t}^{h}\right\} \in G_{t}^{h}} \mathbb{E}_{0} \int_{0}^{\infty} e^{-\rho t}\left[c_{t}^{h}+\Gamma\left(d_{t}^{h}\right)\right] d t
$$

3. Banks $b \in \mathbb{B}$ maximise their market value:

$$
\left\{d_{t}^{b}, k_{t}^{b}, d \delta_{t}^{b}, d \pi_{t}^{b}\right\} \in \arg \sup _{\left\{d_{t}^{b}, k_{t}^{b}, d \delta_{t}^{b}, d \pi_{t}^{b}\right\} \in B_{t}^{b}} \mathbb{E}_{0} \lim _{t \rightarrow \infty} \sup _{\tau} \int_{0}^{\tau \wedge t} e^{-\rho t}\left[d \delta_{t}^{b}-(1+\lambda) d \pi_{t}^{b}\right] d t .
$$

4. All markets clear:

(a) Short-term liabilities:

$$
\int_{\mathbb{H}} d^{h} d h+\int_{\mathbb{B}} d^{b} d b=0
$$

(b) Consumption:

$$
\int_{\mathbb{H}}\left(A-\iota_{t}-\eta\right) k_{t}^{h} d h+\int_{\mathbb{B}}\left(A-\iota_{t}\right) k_{t}^{b} d b=C_{t}^{h}
$$

(c) Capital:

$$
\int_{\mathbb{H}} q_{t} k_{t}^{h} d h+\int_{\mathbb{B}} q_{t} k_{t}^{b} d b=q_{t} K_{t}
$$

\section{F.3 Banks' problem}

For sake of clear notation, I omit all the time subscripts. By standard continuous-time stochastic control methods, the banks HJBE satisfies the following:

$$
\rho J^{b}:=\sup _{\left\{d^{b}, k^{b}, d \Delta^{b}, d \Pi^{b}\right\} \in B^{b}}\left\{d \Delta^{b}-(1+\lambda) d \Pi^{b}+\frac{1}{d t} \mathbb{E} d J^{b}\right\}
$$


Similar to Brunnermeier and Sannikov (2014), it is possible to further characterize (51) by postulating the following form for the value $J^{b}:=\nu(\psi) e^{b}$. Given the guess

$$
\frac{d \nu}{\nu}=\mu^{\nu} d t+\sigma^{\nu} d W
$$

by Itô's Lemma, (51) holds as

$\rho-r=\sup _{\left\{d \delta_{t}^{b}\right\}}\left\{\frac{d \delta^{b}}{\nu}-d \delta^{b}\right\}+\sup _{\left\{d \pi_{t}^{b}\right\}}\left\{d \pi^{b}-(1+\lambda) \frac{d \pi^{b}}{\nu}\right\}+\sup _{\left\{\omega^{b}\right\}}\left\{\omega^{b}\left[\left(\mu^{b}-r\right)-\sigma^{\nu} \sigma^{b}\right]\right\}+\mu^{\nu}$,

where $\omega^{b}=\frac{q k^{b}}{e^{b}}$. Note that we look for the equilibrium at its stationary limit, so that $\frac{\partial J}{\partial t}=0$. By taking the FOCs, the asset pricing, dividends, and equity issuances policies follow naturally. Moreover, under the optimal strategy $\left\{d^{b}, k^{b}, d \Delta^{b}, d \Pi^{b}\right\}$, it hold that

$$
\mu^{\nu}=\rho-r
$$

Note that, in equilibrium, (44) holds, and

$$
\mu^{\nu}=\partial_{d} \Gamma(d)
$$

\section{F.4 The state variable}

Consider the state $\psi=\frac{E^{b}}{K q}$ (we omit the time subscript for sake of clear notation). By Itô's Lemma,

$$
\frac{d \psi}{\psi}=\frac{K q}{E^{b}} \frac{\partial \psi}{\partial E^{b}} d E^{b}+\frac{K q}{E^{b}} \frac{\partial \psi}{\partial K q} d(K q)+\frac{1}{2} \frac{K q}{E^{b}} \frac{\partial^{2} \psi}{\partial(K q)^{2}} d(K q)^{2}
$$

Given that

$$
\frac{d K q}{K q}=\left(\Phi(\iota)+\mu^{q}+\sigma^{q} \sigma\right) d t+\left(\sigma+\sigma_{t}^{q}\right) d W_{t},
$$

and

$$
\frac{d E^{b}}{E^{b}}=r d t+\omega^{b}\left(d R^{i}-r d t\right)-\int_{\mathbb{B}}\left[d \delta^{b}+d \pi^{b}\right] d b
$$


we have that

$$
\begin{aligned}
\frac{d \psi}{\psi}=\underbrace{\left\{\omega^{b} \frac{A-\iota}{q}+\left(\omega^{b}-1\right)\left[\Phi(\iota)+\mu^{q}+\sigma^{q} \sigma-r\right] d t+\left(\sigma+\sigma^{q}\right)^{2}\right\}}_{\mu^{\psi}} d t & \\
& +\underbrace{\left(\omega^{b}-1\right)\left(\sigma+\sigma^{q}\right)}_{\sigma^{\psi}} d W+\underbrace{\int_{\mathbb{B}}\left[d \pi^{b}-d \delta^{b}\right] d b}_{d \Xi} .
\end{aligned}
$$

\section{F.5 Equilibrium dynamics \& numerical solution}

The relative capitalization of the banking sector is the only relevant variable that jointly determines the dynamics of equilibrium prices, i.e. the marginal value of banks' net worth and physical capital. The relationship between $q_{t}, \nu_{t}$ and the state $\psi_{t}$ can be pinned down by Itô's Lemma. The result is summarised in the following Lemma of Proposition 3.

\section{Lemma 1. Equilibrium dynamics}

Given the law of motion of the state $\psi$ in (23), the dynamics of the competitive equilibrium is fully represented by the following system of SDEs:

$$
\begin{gathered}
\frac{d q(\psi)}{q(\psi)}=\mu^{q}(\psi) d t+\sigma^{q}(\psi) d W, \\
\frac{d \nu(\psi)}{\nu(\psi)}=(\rho-r) d t-\sigma^{\nu}(\psi) d W,
\end{gathered}
$$

whose drifts and diffusions solve the following system of ODEs

$$
\left\{\begin{array}{l}
\mu^{q}(\psi)=\frac{\partial_{\psi} q(\psi)}{q(\psi)} \psi \mu^{\psi}(\psi)+\frac{1}{2} \frac{\partial_{\psi \psi} q(\psi)}{q(\psi)}\left[\psi \sigma^{\psi}(\psi)\right]^{2} \\
\mu^{\nu}(\psi)=\frac{\partial_{\psi} \nu(\psi)}{\nu(\psi)} \psi \mu^{\psi}(\psi)+\frac{1}{2} \frac{\partial_{\psi \psi} \nu(\psi)}{\nu(\psi)}\left[\psi \sigma^{\psi}(\psi)\right]^{2} \\
\sigma^{\nu}(\psi)=-\frac{\partial_{\psi} \nu(\psi) \psi}{\nu(\psi)} \sigma^{\psi}(\psi), \\
\sigma^{q}(\psi)=\frac{\partial_{\psi} q(\psi) \psi}{q(\psi)} \sigma^{\psi}(\psi),
\end{array}\right.
$$

with mixed boundary conditions $\lim _{\psi \rightarrow 0} q(\psi)=\frac{A-\eta-\iota(0)}{r-\rho-\Phi(\iota(0))}, \partial_{\psi} q(\bar{\psi})=0$, and $\lim _{\psi \rightarrow 0} \nu(\psi)=$ $1+\lambda, \nu(\bar{\psi})=1, \partial_{\psi} \nu(\bar{\psi})=0$.

Note that the extra boundary condition for $\nu$ is required to pin down $\bar{\psi}$. In fact, the 
dividend payout threshold $\bar{\psi}$ is tracked by smooth pasting at the upper bound $\partial J_{e}=$ $\bar{\psi} \partial \nu(\bar{\psi})+\nu(\bar{\psi})=1 \Rightarrow \partial \nu(\bar{\psi})=0$.

System (52) can be solved numerically by the following procedure similar to the one proposed by Brunnermeier and Sannikov (2014). Let us consider the difference between banks' (21) and households' (17) pricing equations:

$$
\frac{\eta}{q(\psi)}+\rho-r \leq \sigma^{\nu}(\psi)\left(\sigma+\sigma^{q}(\psi)\right)
$$

Moreover, let us define the following auxiliary variable $\kappa(\psi)=\psi \omega^{b}(\psi)$.

The algorithm can be summarised in the following steps:

1. Guess $\partial_{\psi} \nu \in(0,-\infty)$ and $\kappa \in\left[\psi, \psi+\frac{q(\psi)}{\partial_{\psi} q(\psi)}\right]$ so that (53) holds with equality, where $\sigma^{q}(\psi)$ and $\sigma^{\nu}(\psi)$ are pinned down by system $(52)$, and $\sigma^{\psi}(\psi)$ and $\mu^{\psi}(\psi)$ by (24) and (25), respectively;

2. If $\kappa(\psi) \geq 1$, set $\kappa(\psi)=1$ and recompute $(53)$;

3. Solve numerically system (52) where, by considering (44),

$$
\mu^{\nu}=\Gamma
$$

while, by (43),

$$
\mu^{q}(\psi)=\rho+\frac{\eta}{q(\psi)}-\sigma^{q}(\psi) \sigma-\Phi(\iota(\psi))
$$

and stop when either $\partial_{\psi} \nu(\bar{\psi})$ or $\partial_{\psi} q(\bar{\psi})$ (or both) equal zero; ${ }^{22}$

4. Rescale $\nu(\psi)$ so that $\nu(\bar{\psi})=1$ and compute $\omega^{b}=\frac{\kappa(\psi)}{\psi}$;

5. Check whether the initial boundary condition $\lim _{\psi \rightarrow 0} \nu(\psi)=1+\lambda$ is met. If yes, stop. Else, update the initial guess for $\partial_{\psi} \nu$ and repeat from 1.

\footnotetext{
${ }^{22}$ We implement this step via Matlab $O D E 45$.
} 


\section{G Welfare}

Under the optimal strategy $\left\{C^{h}, D^{h}\right\}$, the welfare of households in the aggregate $H$ satisfies (we omit time subscript for sake of clear notation)

$$
E=H\left(\psi, E^{h}\right)=\mathbb{E}_{0} \int_{0}^{\infty} e^{-\rho t}\left[C^{h}+\Gamma\left(D^{h}\right)\right] d t
$$

By market clearing condition for consumption it holds that

$$
C^{h}=K\left[(A-\iota)-\left(1-\psi \omega^{b}\right) \eta\right]
$$

while the aggregate banks' short-term liabilities satisfy

$$
\Gamma\left(D^{h}\right)=\Gamma D^{h}=\omega^{h} \frac{E^{h}}{K q} K q=\psi\left(\omega^{b}-1\right) K q
$$

It follows that

$$
H(\psi, K)=\mathbb{E}_{0} \int_{0}^{\infty} e^{-\rho t} K\left\{[A-\iota(q(\psi))]-\left[1-\omega^{b}(\psi) \psi\right] \eta+\Gamma \psi\left[\omega^{b}(\psi)-1\right] q(\psi)\right\} d t
$$

Feynman-Kac formula, the function $H$ as represented in (54) must solve the following PDE

$$
\begin{aligned}
\rho H(\psi, K)=K \Theta(\psi)+\partial_{\psi} H \psi \mu^{\psi}+\frac{1}{2} \partial_{\psi \psi}^{2} H\left(\psi \sigma^{\psi}\right)^{2}+ & \partial_{K} H K[\Phi(\iota(q(\psi))-\delta]+ \\
& +\frac{1}{2} \partial_{K K}^{2}(K \sigma)^{2}+\partial_{K \psi}^{2} \psi \sigma^{\psi} \sigma K
\end{aligned}
$$

Finally, as the model dynamics is scale invariant in aggregate capital stock, we postulate that $H(\psi, K)=K h(\psi)$. Then, by substituting in (55) and rearranging

$$
\left\{\rho-[\Phi(\iota(q(\psi))-\delta]\} h(\psi)=\Theta(\psi)+\partial_{\psi} h(\psi) \psi\left[\mu^{\psi}+\sigma^{\psi} \sigma\right]+\frac{1}{2} \partial_{\psi \psi}^{2} h\left(\psi \sigma^{\psi}\right)^{2}\right.
$$

with boundary conditions $h(0)=\frac{A-\eta-\iota(0)}{\rho+\delta-\Phi(\iota(0)}$ and $\partial_{\psi} h(0)=0$, where

$$
\Theta(\psi):=[A-\iota(\psi)]-\left[\omega^{b}(\psi) \psi-1\right] \eta+\Gamma \psi q(\psi)\left[\omega^{b}(\psi)-1\right]
$$


Therefore, households' welfare can be written as

$$
K h(\psi, 1)=\mathbb{E} \int_{0}^{\infty} e^{-\rho t} K \Theta(\psi) d t
$$

and

$$
h(\psi, 1)=q(\psi)[1+\psi(\nu(\psi)-1)]
$$

Households' short-run welfare and its components To better understand the elements that contribute at determining households' welfare, the three panels of Figure 9 depicts the a - static - picture of the components of function $\Theta$ in equation (28) as functions of the state $\psi$. In particular, households' welfare is characterized by the flow of consumption $\Theta^{c}$ (left panel) minus the monitoring expenditure $\Theta^{m}$ (middle) plus the utility flow that stems from the liquidity of their holdings in short-term bank liabilities $\Theta^{l}$ (right).

The fist component, consumption flow $\Theta^{c}$, is decreasing in $\psi$ because investments $\iota(\psi)$ are increasing in bank capitalization. In a dynamic perspective, this positively affects the growth rate of capital as well as of banks' relative capitalization. The second component, monitoring $\theta^{m}$, is also increasing in $\psi$. This is because the higher the capitalization of banks', the higher the stock of capital they can deploy to finance firms directly, therefore reducing the resources depleted after monitoring costs by households. The third and last component, liquidity $\Theta^{l}$, is strictly increasing up to the point when banks have sufficient capitalization to absorb households' spare capital through their short-term liabilities. Then, it slightly decreases as the dis-utility of lower relative capitalization $(1-\psi)$ overtakes the benefit of higher prices $q(\psi) \cdot{ }^{23}$

Trivially, when either $\eta$ or $\Gamma$ equal zero, then households do not benefit from banks' capitalization neither through their liquidity services nor through the pecuniary externality of their lower monitoring cost.

\footnotetext{
${ }^{23}$ Note that, when banks have enough capital to absorb households' capital by their liabilities, then $\omega^{b}=\frac{1}{\psi}$. Thus, $\Theta^{l}(\psi) \propto q(\psi)(1-\psi)$. In fact, when $\psi$ approaches $\bar{\psi}, q(\psi)$ progressively slopes towards zero (see also Figure 9, top left panel).
} 

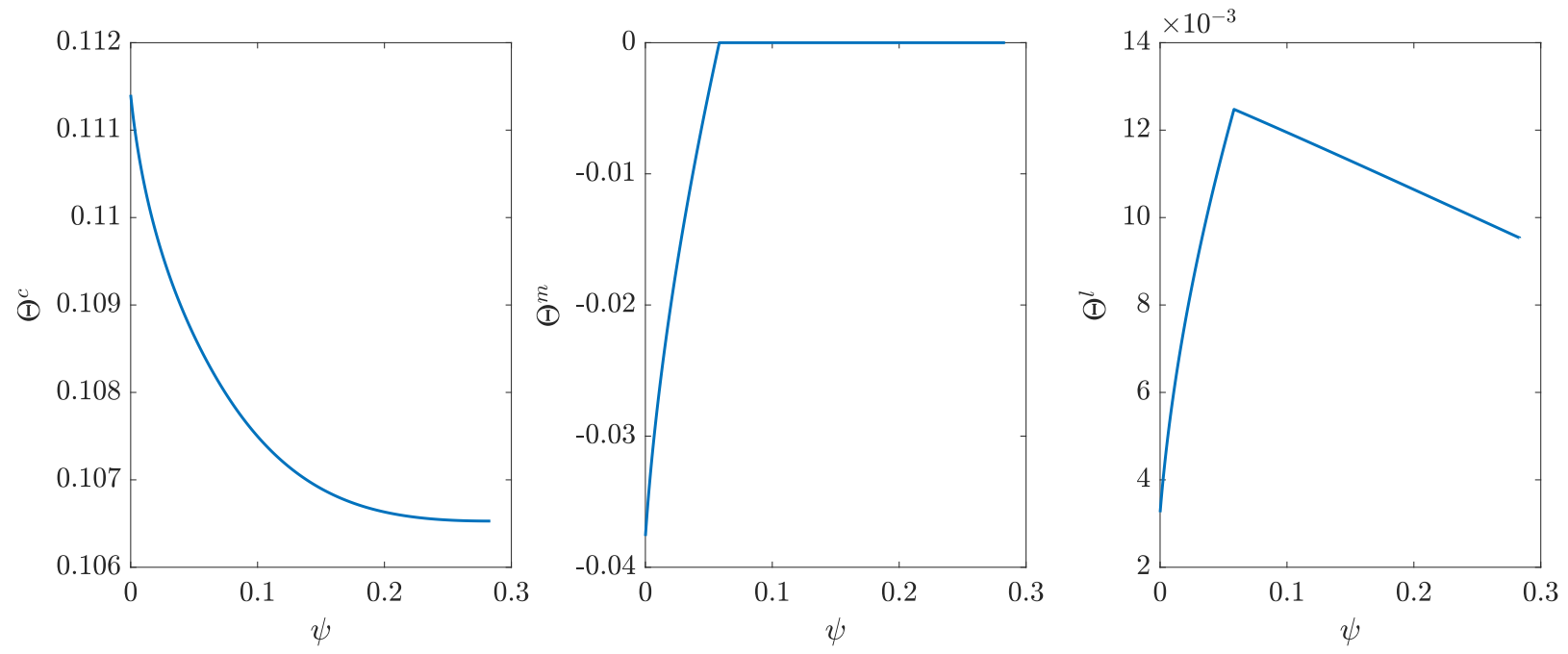

Figure 9: The three components of households' short-run welfare: consumption flow (left panel), monitoring expenditure (middle panel), and liquidity (right panel).

\section{H State dynamics with bailout}

Let $\psi^{\Omega} \geq 0$ be the exogenous bailout thresholds - banking sector minimum require capital buffer - at/below which the government may implement the bailout recapitalization. Let $\psi^{\Omega}:=\frac{E^{b}}{(K q)^{\Omega}}$ be the banks' relative capitalization under the bailout policy $T^{\pi} \geq 0$. Then, the dynamics of the aggregate stock of capital with bailout, henceforth denoted $d(K q)^{\Omega}$, evolves as (we omit time subscripts for sake of clear notation)

$$
\frac{d(K q)^{\Omega}}{(K q)^{\Omega}}=\frac{d(K q)}{K q}-\mathbb{I}_{\psi \leq \psi^{\Omega} \lambda^{G}} \frac{T^{\pi} E^{h}}{(K q)^{\Omega}}
$$

because $d T^{\pi} \lambda^{G}$ resources are lost after bailout administrative costs.

Likewise, aggregate banks' equity evolves as (see also Equation 12)

$$
\frac{d E^{b}}{E^{b}}=\frac{d E^{b}}{E^{b}}+\mathbb{I}_{\psi \leq \psi^{\Omega}} \frac{T^{\pi} E^{h}}{E^{b, \Omega}}
$$

By Itô's Lemma (see also Appendix F.4), the dynamics of relative banking sector capitalization with bailout reads as

$$
\frac{d \psi^{\Omega}}{\psi^{\Omega}}=\frac{d \psi}{\psi}+\mathbb{I}_{\psi \leq \psi^{\Omega}} T^{\pi}\left(\frac{E^{h}}{E^{b}}+\lambda^{G} \frac{E^{h}}{K q}\right) d t
$$




$$
\frac{d \psi^{\Omega}}{\psi^{\Omega}}=\frac{d \psi}{\psi}+\mathbb{I}_{\psi \leq \psi^{\Omega}} T^{\pi}(1-\psi)\left(\frac{1}{\psi}+\lambda^{G}\right) d t
$$




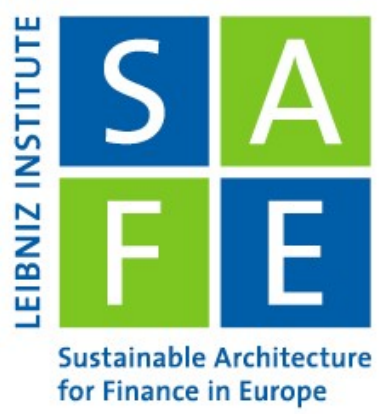

\section{Recent Issues}

No. 291 Loriana Pelizzon, Satchit Sagade, Katia Vozian

No. 290 Nicola Fuchs-Schündeln, Dirk Krueger, Alexander Ludwig, Irina Popova

No. 289 Christian Schlag, Michael Semenischev, Julian Thimme

No. 288 Michele Costola, Michael Nofer, Oliver Hinz, Loriana Pelizzon

No. 287 Kevin Bauer, Nicolas Pfeuffer, Benjamin M. Abdel-Karim, Oliver Hinz, Michael Kosfeld

No. 286 Andreass Hackethal, Michael Kirchler, Christine Laudenbach, Michael Razen, Annika Weber

No. 285 Elena Carletti, Tommaso Oliviero, Marco Pagano, Loriana Pelizzon, Marti G. Subrahmanyam

No. 284 Monica Billio, Michele Costola, Iva Hristova, Carmelo Latino, Loriana Pelizzon

No. 283 Jannis Bischof, Christian Laux, Christian Leuz

No. 282 Daniel Munevar, Grygoriy Pustovit

No. 281 Kevin Bauer

No. 280 Konstantin Bräuer, Andreas Hackethal, Tobin Hanspal
Resiliency: Cross-Venue Dynamics with Hawkes Processes

The Long-Term Distributional and Welfare Effects of Covid-19 School Closures

Predictability and the Cross-Section of Expected Returns: A Challenge for Asset Pricing Models

Machine Learning Sentiment Analysis, COVID-19 News and Stock Market Reactions

The Terminator of Social Welfare? The Economic Consequences of Algorithmic Discrimination

On the (Ir)Relevance of Monetary Incentives in Risk Preference Elicitation Experiments

The COVID-19 Shock and Equity Shortfall: Firm-Level Evidence from Italy

Inside the ESG Ratings: (Dis)agreement and Performance

Accounting for Financial Stability: Bank Disclosure and Loss Recognition in the Financial Crisis

Back to the Future: A Sovereign Debt Standstill Mechanism IMF Article VIII, Section 2 (b)

How did we do? The Impact of Relative Performance Feedback on Intergroup Hostilities

Consuming Dividends 